Board of Governors of the Federal Reserve System

International Finance Discussion Papers

Number 875

September 2006

\title{
A Bivariate Model of Fed and ECB Main Policy Rates
}

\author{
Chiara Scotti
}

NOTE: International Finance Discussion Papers are preliminary materials circulated to stimulate discussion and critical comment. References in publications to International Finance Discussion Papers (other than an acknowledgment that the writer has had access to unpublished material) should be cleared with the author or authors. Recent IFDPs are available on the Web at www.federalreserve.gov/pubs/ifdp/. This paper can be downloaded without charge from Social Science Research Network electronic library at http://www.ssrn.com/. 


\title{
A Bivariate Model of Fed and ECB Main Policy Rates
}

\author{
Chiara Scotti* \\ Federal Reserve Board
}

\begin{abstract}
This paper studies when and by how much the Fed and the ECB change their target interest rates. I develop a new nonlinear bivariate framework, which allows for elaborate dynamics and potential interdependence between the two countries, as opposed to linear feedback rules, such as a Taylor rule, and I use a novel real-time data set. A Bayesian estimation approach is particularly well suited to the small data sample. Empirical results support synchronization between the central banks and non-zero correlation between magnitude shocks, but they do not support follower behavior. Institutional factors and inflation represent relevant variables for timing decisions of both banks. Inflation rates are important factors for magnitude decisions, while output plays a major role in US magnitude decisions.
\end{abstract}

JEL Classification: C11, C3, C52, E52

Keywords: Monetary Policy, Copula, Hazard Probability, Bivariate Probit Models

\footnotetext{
${ }^{*}$ I would like to thank Francis X. Diebold, Jesús Fernández-Villaverde and Frank Schorfheide for their invaluable advice. Celso Brunetti, Fabio Canova, Mark Carey, Michael Ehrmann, Gregory Kordas, Jean-Philippe Laforte, Mico Loretan, John Rogers and Robert Vigfusson provided useful comments. Part of this research was conducted while I was at the European Central Bank, for whose hospitality I am thankful. The views expressed in this paper are solely the responsibility of the author and should not be interpreted as reflecting the view of the Board of Governors of the Federal Reserve System or of any other person associated with the Federal Reserve System. Correspondence to: Chiara Scotti, Mail Stop 18, Federal Reserve Board, Washington DC 20551. E-Mail: chiara.scotti@frb.gov
} 


\section{Introduction}

This paper focuses on the Federal Reserve (Fed) and the European Central Bank (ECB) interest rate feedback rules. In particular, it develops an econometric model that empirically analyzes when a target rate change is adopted (timing), as well as by how much the rate is changed (magnitude change). While central banks' behavior has typically been described with the use of univariate linear interest-rate feedback rules, such as Taylor rules, I exploit a nonlinear bivariate framework, which allows for elaborate dynamics and for potential interactions between the two central banks.

This study is appealing for several reasons. The most important way the Fed and the ECB express their monetary policy goals is by setting, respectively, the Federal Funds Target Rate (FFTR) and the Main Refinancing Operation (MRO) rate. ${ }^{1}$ These policy rates are important because they signal the stance of monetary policy, affect investment decisions, and often have considerable impact on financial markets. Understanding the way the two central banks set their target rates and identifying the variables taken into account in the process is of great interest. Since it started to operate at the beginning of 1999, the ECB, together with the Fed, has been meticulously scrutinized in the way it conducts monetary policy. Bartolini and Prati (2003) analyze the Fed and the ECB with particular attention to institutional structures, policy frameworks, and operational procedures. Cecchetti and O'Sullivan (2003) compare the central banks' approaches to the execution of monetary policy. US and EMU policy rates followed a roughly similar pattern over the period January $1^{\text {st }}$, 1998 to March $25^{\text {th }}$, 2005 - see Figure 1. The EMU rate fluctuates over a narrower range than the US rate; both rates are characterized by frequent changes in the first half of the sample and sporadic changes in the middle part of the sample; the FFTR displays frequent changes also in the last part of the sample, while the EMU rate is held constant for a long period of time. ${ }^{2}$ In addition, the size and sign of interest rate changes display some similarities. My analysis addresses these issues by studying when interest rate changes are implemented and by examining the size and sign of those changes, with the idea that the two decisions could carry distinct information and might be triggered by different variables. ${ }^{3}$

\footnotetext{
${ }^{1}$ In particular, the Federal Open Market Committee (FOMC) implements its monetary policy decisions by changing its target for the federal funds rate (FFR), which is the rate at which depository institutions borrow and lend reserves to and from each other overnight. Although the Federal Reserve does not control the FFR directly, it can do so indirectly by varying the supply of reserves available to be traded in the market. On the other hand, the key policy rate set by the Governing Council of the ECB is the rate applied to main refinancing operations, which provide the bulk of liquidity to the financial system.

For more information about how the Fed and the ECB operate, see the appendix

${ }^{2}$ Please note that the sample only includes the first part of the 2004 through 2006 tightening cycle .

${ }^{3}$ In a traditional approach (e.g. VAR or Taylor rule), the same variables affect both timing and magnitude because the two decisions are normally analyzed together. That is, when there is a jump/change in the rate (magnitude decision), the event is considered to occur (timing decision).
} 
Open questions in the monetary policy debate are whether in an open economy interest rate feedback rules should include the exchange rate, in addition to inflation and output, and, more generally, how optimal interest rate feedback rules should be designed within an international framework - see, among others, Clarida et al. (2002), Benigno (2002), and Pappa (2004). While the theoretical literature has focused on optimality issues, this papers introduces a new methodology to provide evidence about the interaction between the Fed and the ECB. It does not address issues related to cooperation or potential gains from cooperation. This paper only provides stylized facts about Fed and ECB interest rate feedback rules, exploring the possibility that interdependence could play a role in describing timing and magnitude of interest rate changes.

Moreover, it is not clear that conventional linear interest rate feedback rules are sufficient to explain the complexity of central banks' behavior, especially in the presence of potential interdependences. I therefore investigate the possibility that a nonlinear model could better describe interest rate decisions.

Methodologically, one novelty of the paper is to provide a Bivariate Autoregressive Conditional Hazard $(\mathrm{BACH})$ model to study the timing of interest rate changes and a Conditional Bivariate Ordered (CBO) Probit model to analyze the magnitude of interest rate changes. The $\mathrm{BACH}$ model extends the Autoregressive Conditional Hazard (ACH) model of Hamilton and Jordà (2002) in order to account for interdependence between the two central banks. The timing/duration framework is based on the Autoregressive Conditional Duration (ACD) model developed by Engle and Russell (1998a, 1998b) and Engle (2000). Bergin and Jordà (2003) analyze empirical evidence of monetary policy interdependence within a set of 14 OECD countries, making use of the Hamilton and Jordà (2002) model, but they do not analyze the EMU. They study interdependence by investigating whether the probability of a change in the domestic target rate at time $t$ depends on a similar decision by a "leading country" at time $t-1$ (US, Germany or Japan). This implies a hierarchy between banks and assumes that the leading central bank's decision is known by the other central bank. Moreover, their setup does not allow them to recover a joint hazard probability for the two central banks. My model differs from Bergin and Jordà (2003) because it is a truly bivariate model which converts the marginal hazards to a joint hazard probability through the use of a conditional discrete copula-type representation. This allows me to treat the Fed and ECB symmetrically and to study interdependence in the form of decision synchronization and follower behaviors. The CBO Probit model represents a special case of a Bivariate Ordered Probit model, where I rescale the probability mass to condition on the timing decision. It differs from Bergin and Jordà (2003) because, by rescaling, I am able to study the exact magnitude of the change (basis points change) as opposed to merely the direction of change (strong increase, increase, decrease, strong decrease).

According to the Taylor-type rule literature, past interest rates, inflation, output gaps, and 
exchange rate movements are relevant factors in choosing the level of interest rate changes. I analyze whether these variables are important in determining when the Fed and ECB change their interest rates, as well as whether they play a role in explaining the magnitude of the change. Moreover, I study whether the Fed and the ECB synchronize their policies, whether one follows the other, and whether there exists a contemporaneous correlation in the magnitude of their interest rate changes. Timing synchronization of policies is analyzed with the odds ratio, which indicates how much the odds of one bank changing its target rate move when the other bank changes its target. Follower behavior is studied with dummy variables that capture the effect of one country's interest rate decision on the subsequent decisions of the other country. A test on the coefficient of this dummy variable can be interpreted as a test of one country (Granger) causing the other country's interest rate decision, and hence one country following the other country's decision. The correlation between interest rate changes captures the correlation which is left unexplained after traditional explanatory variables have been considered. This paper shows whether the traditional variables that have commonly been used in the literature, are sufficient in explaining timing and magnitude changes of policy rates, and whether the interdependence could be a factor in explaining monetary policies. However, it does not provide a complete answer to the underlying problem about what is in fact the source of the interdependence and whether interdependence is optimal.

Another novel feature of the paper is the empirical application with the use of a real-time data set and the Bayesian estimation. Persuaded that the available information set that central banks observe is of great importance to the decisions they make, I construct and use a real-time data set that includes output and inflation measures, exchange rates and data on target rates and duration between changes. This real time approach to monetary policy has been studied, among others, by Orphanides (2001), who demonstrates that real-time policy recommendations differ from those derived with ex-post revised data. ${ }^{4}$ Bayesian estimation is not new to monetary policy studies (see Cogley and Sargent 2002, Schorfheide 2006, and Sims and Zha 1998), but, to the best of my knowledge, it has never been applied to ACD- or ACH-type models. The methods used in the paper generally require fairly large samples to produce results. Because of the youth of the ECB and the type of data, the sample used in the paper is small. The Bayesian framework is particularly well suited to this small sample problem, because it allows me to incorporate presample information to better evaluate the available information. I use ten years of data for the Fed and the Bundesbank to elicit the prior, following the view that the German central bank is, among the European central banks, the one that most closely resembles the ECB. Although the Bayesian approach facilitates the estimation, it does not completely eliminate the small sample

\footnotetext{
${ }^{4}$ It could be interesting to compare baseline results based on real-time data to results obtained by estimating the model using revised data. However, this goes beyond the scope of this paper. Many papers in the literature have in fact already addressed this issue.
} 
problem.

Estimation results confirm that ACH-type models need long data samples. However, the timing model results seem to support the hypothesis that institutional factors, such as scheduled meetings of the FOMC and the Governing Council, as well as inflation rates, are important variables in determining timing decisions. Timing synchronization between the two central banks is supported, even after removing the September 2001 coordination attempt. On the other hand, follower behaviors are not supported, rejecting therefore the hypothesis that the ECB follows the Fed or vice versa. Estimation results for the magnitude model illustrate the importance of inflation rates as explanatory variables for both countries. Output turns out to be a major determinant of Fed but not of ECB magnitude decisions, confirming the idea that the ECB's primary objective is to maintain price stability. I find evidence supporting non-zero correlation between the magnitude shocks. The positive correlation suggests that the interest rate feedback rules containing inflation, output, and the exchange rate might not capture the interdependence in the level decisions.

The paper is organized as follows. The next section describes the model. Section 3 describes the data. Section 4 describes the Bayesian implementation and presents empirical results. Section 5 presents a comparison with a traditional Vector Autoregression approach. Section 6 concludes.

\section{The Model}

For simplicity I refer to the US and the EMU as countries $a$ and $b$. The basic idea is to separate timing and magnitude of interest rate changes, and to derive a model capable of accounting for the specific features of both decisions. I describe timing by binary variables that take the value one when the target interest rate is changed. Consequently, magnitude variables take non-zero values only when the timing binary variable is one.

More precisely, let $x_{t}^{i}$ be a binary variable that takes values $\{0,1\}$ according to whether the target rate of country $i \in\{a, b\}$ has changed at calendar time $t$ :

$$
x_{t}^{i}= \begin{cases}1 & \text { target rate of country } i \text { is changed } \\ 0 & \text { otherwise }\end{cases}
$$

and let $y_{t}^{i}$ be the interest rate change that takes place whenever event $x^{i}$ occurs (i.e. whenever $\left.x^{i}=1\right)$.

I am interested in studying whether the two central banks decide to change their target rate $(x)$ and by how much $(y)$; hence I want to study the joint probability $f\left(x_{t}^{a}, x_{t}^{b}, y_{t}^{a}, y_{t}^{b} \mid \mathcal{F}_{t-1}\right)$, where $\mathcal{F}_{t-1}$ is the information set available at time $t-1$. The joint probability can be rewrit- 
ten as the product of the marginal distribution of $\left(x^{a}, x^{b}\right)$ and the conditional distribution of $\left(y^{a}, y^{b} \mid x^{a}, x^{b}\right)$ :

$$
f\left(x_{t}^{a}, x_{t}^{b}, y_{t}^{a}, y_{t}^{b} \mid \mathcal{F}_{t-1} ; \theta\right)=g\left(x_{t}^{a}, x_{t}^{b} \mid \mathcal{F}_{t-1} ; \theta_{1}\right) \cdot q\left(y_{t}^{a}, y_{t}^{b} \mid x_{t}^{a}, x_{t}^{b}, \mathcal{F}_{t-1} ; \theta_{2}\right)
$$

so that the resulting log-likelihood can be decomposed into two parts

$$
\mathcal{L}\left(\theta_{1}, \theta_{2}\right)=\mathcal{L}_{1}\left(\theta_{1}\right)+\mathcal{L}_{2}\left(\theta_{2}\right)
$$

where

$$
\begin{aligned}
& \mathcal{L}_{1}\left(\theta_{1}\right)=\sum_{t=1}^{T} \log g\left(x_{t}^{a}, x_{t}^{b} \mid \mathcal{F}_{t-1} ; \theta_{1}\right) \quad \text { Timing Model } \\
& \mathcal{L}_{2}\left(\theta_{2}\right)=\sum_{t=1}^{T} \log q\left(y_{t}^{a}, y_{t}^{b} \mid x_{t}^{a}, x_{t}^{b}, \mathcal{F}_{t-1} ; \theta_{2}\right) \quad \text { Level Model. }
\end{aligned}
$$

As pointed out by Engle (2000), if $\theta_{1}$ and $\theta_{2}$ have no parameters in common and are variation free, the maximization of $\mathcal{L}\left(\theta_{1}, \theta_{2}\right)$ is equivalent to maximizing $\mathcal{L}_{1}\left(\theta_{1}\right)$ and $\mathcal{L}_{2}\left(\theta_{2}\right)$ separately.

I refer to the first part of the likelihood as the Timing Model and to the second part as the Level Model. The former is characterized as a Bivariate Autoregressive Conditional Hazard $(\mathrm{BACH})$ model, while the latter is a Conditional Bivariate Ordered (CBO) Probit model.

I describe both models below.

\subsection{Bivariate Autoregressive Conditional Hazard (BACH) Model}

The Timing model hinges on the joint probability of type $a$ and $b$ events occurring, where type $i$ event occurring means that country $i, i \in\{a, b\}$, has decided to change its target rate. Marginal probability distributions for individual interest rate decisions have been modeled in the literature with Autoregressive Conditional Hazard (ACH) models - see Hamilton and Jordà (2002). The ACH model is derived from the Autoregressive Conditional Duration (ACD) model proposed by Engle and Russell (1998a, 1998b) and Engle (2000). The ACD model is developed in event time $^{5}$ and aims to explain the duration of spells between events (between two consecutive trades or quotes, for example). It is called autoregressive conditional duration because the conditional expectation of the duration depends upon past durations. Within this duration framework, bivariate models have been studied, but none of them is suitable to the present framework. Engle and Lunde (2003), for example, model the joint likelihood function for trade and quote arrivals, but they include the possibility that an intervening trade censors the time between a

\footnotetext{
${ }^{5}$ Event time is defined by a sequence $\left\{t_{0}, t_{1}, . ., t_{n}, \ldots\right\}$ with $t_{0}<t_{1}<\ldots<t_{n}<\ldots$ representing the arrival time of an event. Calendar time is simply $t=0,1,2,3, \ldots, n, \ldots$
} 
trade and the subsequent quote. ${ }^{6}$ Thus their model does not serve my purpose. Moreover, unlike them, I adopt calendar time because it readily allows me to incorporate updated explanatory variables.

I develop a bivariate model which converts the marginal distribution information, modelled following Hamilton and Jordà (2002), into a joint distribution, by using a conditional discrete copula-type representation.

\subsubsection{Marginal Hazard Rates}

Define $N^{a}(t)$ and $N^{b}(t)$ to be, respectively, the cumulative number of country $a$ and $b$ events as of time $t$, i.e. the number of target rate changes of country $a$ and $b$ as of time $t$. Following Hamilton and Jordà (2002), I rewrite the $A C D(r, m)$ model from Engle and Russel (1998) as

$$
\begin{aligned}
\psi_{N^{i}(t)}^{i} & =\sum_{j=1}^{m^{i}} \alpha_{j}^{i} u_{N^{i}(t)-j}^{i}+\sum_{j=1}^{r^{i}} \beta_{j}^{i} \psi_{N^{i}(t)-j}^{i} \\
i & =a, b
\end{aligned}
$$

where $\alpha^{i}$ and $\beta^{i}$ are country specific parameters, $\psi_{N^{i}(t)}^{i}$ is the expected duration for country $i$ at calendar time $t$ when $N^{i}(t)$ events have occurred and $u_{N^{i}(t)-j}^{i}$ is the duration for country $i$ when $N^{i}(t)-j$ events have occurred, i.e. $u_{N^{i}(t)-j}^{i}$ is the time elapsed between event $N^{i}(t)-j-1$ and event $N^{i}(t)-j$. Viewed as a function of time, $\psi_{N^{i}(t)}^{i}$ is a step function that changes only when a new event occurs, i.e. when $N^{i}(t) \neq N^{i}(t-1)$.

Define the hazard rate $h_{t}^{i}$ as the probability of a country $i$ event occurring at time $t$ (the probability that the central bank of country $i$ decides to change its target rate), given the information available up until time $t-1$, i.e. $\operatorname{Pr}\left(x_{t}^{i}=1 \mid \mathcal{F}_{t-1}\right)$. The country $i$ marginal hazard rate can be written as

$$
\begin{aligned}
h_{t \mid t-1}^{i} & =\operatorname{Pr}\left[N^{i}(t) \neq N^{i}(t-1) \mid \mathcal{F}_{t-1}\right]=\operatorname{Pr}\left[x_{t}^{i}=1 \mid \mathcal{F}_{t-1}\right] \\
& =\frac{1}{\psi_{N^{i}(t-1)}^{i}+\delta_{i}^{\prime} z_{t-1}}
\end{aligned}
$$

where

$$
\begin{aligned}
\psi_{N^{i}(t-1)}^{i} & =\alpha^{i} u_{N^{i}(t-1)-1}^{i}+\beta^{i} \psi_{N^{i}(t-1)-1}^{i} \\
r & =m=1
\end{aligned}
$$

\footnotetext{
${ }^{6}$ In particular, they analyse the elapsed times between two consecutive trades and between a trade and a quote.
} 
$z_{t-1}$ is a vector of variables known at $t-1$ and $\delta_{i}$ is a parameter vector. ${ }^{7}$

Using the above marginal distributions for the Bernoulli variables $x^{i}, i=a, b$, I want to construct a joint distribution for $\left(x^{a}, x^{b}\right)$. The following section gives some theoretical background about the discrete copula-type representation that will allow me to recover the joint hazard of countries $a$ and $b$.

\subsubsection{Conditional Discrete Copula-Type Representation and Joint Hazard Rates}

When marginal distributions are continuous, a joint distribution can be recovered from the marginal distributions with the use of a copula. The beauty of a copula is that for bivariate (multivariate) distributions, the univariate marginals and the dependence structure can be separated, with the copula containing all the dependence information. Since the marginals considered here are discrete, problems arise since copulas are not unique in this case. The way I solve the problem follows Tajar et al. (2001). As the copula contains the dependence information, Tajar et al. disentangle the dependence structure from the Bernoulli marginals.

In addition, I extend the existing results to allow for conditioning variables. For the purpose of exposition I will assume below that $\mathcal{F}$ represents the conditioning set (it might contain one or more variables).

Let $\left(x^{a}, x^{b}\right)$ be random Bernoulli variables for which the marginal conditional distributions $\operatorname{Pr}\left[x_{t}^{a} \mid \mathcal{F}\right]$ and $\operatorname{Pr}\left[x_{t}^{b} \mid \mathcal{F}\right]$ are known. Associate $\left(x^{a}, x^{b}\right) \mid \mathcal{F}$ to a random couple $\left(u^{a}, u^{b}\right) \mid \mathcal{F}$ with discrete uniform marginals such that

$$
\operatorname{Pr}\left[u^{a}=0 \mid \mathcal{F}\right]=\operatorname{Pr}\left[u^{a}=1 \mid \mathcal{F}\right]=\operatorname{Pr}\left[u^{b}=0 \mid \mathcal{F}\right]=\operatorname{Pr}\left[u^{b}=1 \mid \mathcal{F}\right]=\frac{1}{2} .
$$

Therefore the joint distributions of $\left(x^{a}, x^{b}\right) \mid \mathcal{F}$ and $\left(u^{a}, u^{b}\right) \mid \mathcal{F}$ can be written as follows

\begin{tabular}{|c|c|c|c|}
\hline$x_{\mid \mathcal{F}}^{a} \backslash x_{\mid \mathcal{F}}^{b}$ & 0 & 1 & \\
\hline 0 & $h_{00 \mid \mathcal{F}}$ & $h_{01 \mid \mathcal{F}}$ & $1-h_{\mid \mathcal{F}}^{a}$ \\
\hline 1 & $h_{10 \mid \mathcal{F}}$ & $h_{11 \mid \mathcal{F}}$ & $h_{\mid \mathcal{F}}^{a}$ \\
\hline & $1-h_{\mid \mathcal{F}}^{b}$ & $h_{\mid \mathcal{F}}^{b}$ & \\
\hline
\end{tabular}

\footnotetext{
${ }^{7}$ I need to ensure that $h_{t \mid t-1}^{i} \in(0,1)$. To do so I follow Hamilton and Jordà $(2002)$ and I use a smooth function $\lambda$ so that

where

$$
h_{t \mid t-1}^{i}=\frac{1}{\lambda\left(\psi_{N^{i}(t-1)}^{i}+\delta_{i}^{\prime} z_{t-1}\right)}
$$

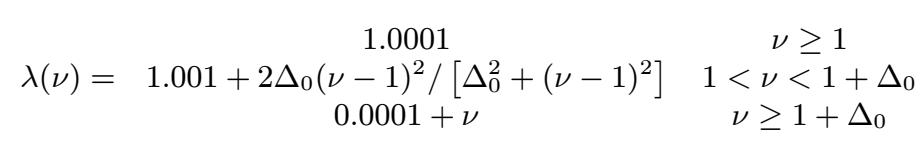

and $\Delta_{0}=0.1$
} 


\begin{tabular}{|c|c|c|c|}
\hline$u_{\mid \mathcal{F}}^{a} \backslash u_{\mid \mathcal{F}}^{b}$ & 0 & 1 & \\
\hline 0 & $\gamma_{00 \mid \mathcal{F}}$ & $\gamma_{01 \mid \mathcal{F}}$ & $1 / 2$ \\
\hline 1 & $\gamma_{10 \mid \mathcal{F}}$ & $\gamma_{11 \mid \mathcal{F}}$ & $1 / 2$ \\
\hline & $1 / 2$ & $1 / 2$ & \\
\hline
\end{tabular}

The joint probabilities of $\left(x^{a}, x^{b}\right) \mid \mathcal{F}$ and $\left(u^{a}, u^{b}\right) \mid \mathcal{F}$ are such that

$$
h_{l k \mid \mathcal{F}}=\left(p_{l \mid \mathcal{F}}^{a}\right) \cdot\left(p_{k \mid \mathcal{F}}^{b}\right) \cdot\left(\gamma_{l k \mid \mathcal{F}}\right), l, k=0,1
$$

where $p_{l \mid \mathcal{F}}^{a}$ and $p_{k \mid \mathcal{F}}^{b}$ depend only on the marginals, while $\gamma_{l k \mid \mathcal{F}}$ contains the dependence information.

I compute the $p^{\prime}$ s from the marginals as

$$
\begin{aligned}
& p_{0 \mid \mathcal{F}}^{a}=\frac{\left(1-h_{\mid \mathcal{F}}^{a}\right)}{n f_{1}}, p_{1 \mid \mathcal{F}}^{a}=\frac{h_{\mid \mathcal{F}}^{a}}{n f_{2}} \\
& p_{0 \mid \mathcal{F}}^{b}=\frac{\left(1-h_{\mid \mathcal{F}}^{b}\right)}{n f_{3}}, \quad p_{1 \mid \mathcal{F}}^{b}=\frac{h_{\mid \mathcal{F}}^{b}}{n f_{4}}
\end{aligned}
$$

where $n f_{p}, p=1,2,3,4$ are normalizing factors that guarantee $h_{00}+h_{01}=1-h^{a}, h_{10}+h_{11}=$ $h^{a}, h_{00}+h_{10}=1-h^{b}, h_{01}+h_{11}=h^{b}$.

Let the odds ratio $r \in R^{+}$be

$$
r=\frac{h_{00 \mid \mathcal{F}} \cdot h_{11 \mid \mathcal{F}}}{h_{01 \mid \mathcal{F}} \cdot h_{10 \mid \mathcal{F}}}=\frac{\gamma_{00 \mid \mathcal{F}} \cdot \gamma_{11 \mid \mathcal{F}}}{\gamma_{01 \mid \mathcal{F}} \cdot \gamma_{10 \mid \mathcal{F}}}
$$

The odds ratio is a measure of association for binary random variables. For ease of interpretation, it can be rewritten as $r=\frac{\left(\gamma_{11 \mid \mathcal{F}} / \gamma_{10 \mid \mathcal{F}}\right)}{\left(\gamma_{01 \mid \mathcal{F}} / \gamma_{00 \mid \mathcal{F}}\right)}$, where the numerator gives the "odds" of country $b$ event occurring versus not occurring given that country $a$ event occurs, while the denominator gives the "odds" of country $b$ event occurring given that country $a$ event does not occur. Thus the odds ratio indicates how much the odds of country $b$ changing its target rate increase when country a changes its target. Independence is $r=1$.

For a pair of binary random variables with uniform marginals the following property holds:

$$
\gamma_{01 \mid \mathcal{F}}=\frac{1}{2}-\gamma_{00 \mid \mathcal{F}}, \quad \gamma_{10 \mid \mathcal{F}}=\frac{1}{2}-\gamma_{00 \mid \mathcal{F}}, \quad \gamma_{11 \mid \mathcal{F}}=\gamma_{00 \mid \mathcal{F}}
$$

Therefore, $\gamma_{00 \mid \mathcal{F}}$ can be obtained as the solution ${ }^{8}$ to the following quadratic equation

$$
\gamma_{00 \mid \mathcal{F}}^{2}(r-1)-r \gamma_{00 \mid \mathcal{F}}+\frac{r}{4}=0 .
$$

\footnotetext{
${ }^{8}$ Only one of the two roots belongs to $[0,1 / 2)$ and is therefore admissible. The root $\gamma_{00, t}^{+} \notin[0,1 / 2)$.
} 
Hence $h_{i j \mid \mathcal{F}} i, j=0,1$ can be computed.

This copula-type representation allows me to construct the joint hazard rates to be used in the likelihood.

Some assumptions must be made. First, in my setup, both marginals depend on $t$. According to equation (15), the odds ratio should also depend on $t$. I instead assume that $r_{t}=r, \forall t$. Second, I define the conditioning set $\mathcal{F}$ as the information available as of time $t-1$. The conditioning set must be the same for both marginal distributions. ${ }^{9}$

Therefore, the joint probability of events $a$ and $b$ occurring (given $\mathcal{F}_{t-1}$ ) is:

$$
\begin{aligned}
g\left(x_{t}^{a} x_{t}^{b} \mid \mathcal{F}_{t-1} ; \theta_{1}\right)= & \left(h_{00, t \mid t-1}\right)^{1\left[x_{t}^{a}=0, x_{t}^{b}=0\right]}\left(h_{10, t \mid t-1}\right)^{1\left[x_{t}^{a}=1, x_{t}^{b}=0\right]} \\
& \left(h_{01, t \mid t-1}\right)^{1\left[x_{t}^{a}=0, x_{t}^{b}=1\right]}\left(h_{11, t \mid t-1}\right)^{1\left[x_{t}^{a}=1, x_{t}^{b}=1\right]}
\end{aligned}
$$

where $1[\cdot, \cdot]$ is an indicator function. Equation 18 yields the following likelihood function:

$$
\mathcal{L}_{1}\left(\theta_{1}\right)=\sum_{t=1}^{T}\left\{\begin{array}{c}
1\left[x_{t}^{a}=0, x_{t}^{b}=0\right] \log \left(h_{00, t \mid t-1}\right) \\
+1\left[x_{t}^{a}=1, x_{t}^{b}=0\right] \log \left(h_{10, t \mid t-1}\right) \\
+1\left[x_{t}^{a}=0, x_{t}^{b}=1\right] \log \left(h_{01, t \mid t-1}\right) \\
+1\left[x_{t}^{a}=1, x_{t}^{b}=1\right] \log \left(h_{11, t \mid t-1}\right)
\end{array}\right\}
$$

\subsection{Conditional Bivariate Ordered (CBO) Probit}

I use a special bivariate ordered Probit model to analyze the interest rate magnitude changes $\left(y_{t}^{a}\right.$ and $\left.y_{t}^{b}\right)$.

My framework is a special case of the standard bivariate ordered Probit, because I am interested in the distribution of $y_{t}^{a}$ and $y_{t}^{b}$ conditioned on the information set $\mathcal{W}_{t-1}$ and conditioned on the timing decision $\left(x_{t}^{a}, x_{t}^{b}\right)$.

Assume there are two latent variables, one for each country, representing the optimal (but unobserved) target change

$$
\begin{aligned}
& \widetilde{y}_{t}^{a}=w_{t-1}^{a}{ }^{\prime} \pi^{a}+\varepsilon_{t}^{a} \\
& \widetilde{y}_{t}^{b}=w_{t-1}^{b}{ }^{\prime} \pi^{b}+\varepsilon_{t}^{b}
\end{aligned}
$$

where $\pi^{a}$ and $\pi^{b}$ are parameter vectors, $w_{t-1}^{a}$ and $w_{t-1}^{b} \in \mathcal{W}_{t-1}$ are vectors of variables observed as of time $t-1$, and $\left(\varepsilon_{t}^{a}, \varepsilon_{t}^{b}\right) \mid w_{t-1}, \sim \mathcal{N}(0, \Sigma)$ with $\Sigma=\left[\begin{array}{ll}1 & \rho \\ \rho & 1\end{array}\right]$.

\footnotetext{
${ }^{9}$ Thus in principle the marginal hazard rate for process $a, h^{a}$, depends on all the conditioning variables (even the one from process $b$ ). I will impose the restriction that process $b$ variables have no effect on the duration. The same applies to $h^{b}$.
} 
If the observable target change $y_{t}^{i}$ could assume the discrete values $s^{i} \in\{-50,-25,0,25,50\}$ measured in basis points (bps), $i=a, b$, then it would be related to the unobservable optimal target change, so that

$$
y_{t}^{i}= \begin{cases}s_{1}=-50 & \text { if } \widetilde{y}_{t}^{i} \in\left(-\infty=c_{0}^{i}, c_{1}^{i}\right] \\ s_{2}=-25 & \text { if } \widetilde{y}_{t}^{i} \in\left(c_{1}^{i}, c_{2}^{i}\right] \\ s_{3}=0 & \text { if } \widetilde{y}_{t}^{i} \in\left(c_{2}^{i}, c_{3}^{i}\right] \\ s_{4}=25 & \text { if } \widetilde{y}_{t}^{i} \in\left(c_{3}^{i}, c_{4}^{i}\right] \\ s_{5}=50 & \text { if } \widetilde{y}_{t}^{i} \in\left(c_{4}^{i}, c_{5}^{i}=\infty\right) .\end{cases}
$$

I observe $x_{t}^{a}$ and $x_{t}^{b}$ and am interested in the conditional distribution of $y_{t}^{a}$ and $y_{t}^{b}$ given $x_{t}^{a}$ and $x_{t}^{b}$. The questions I want to address are: what is the joint probability of $y_{t}^{a}$ and $y_{t}^{b}$ taking values $s_{m}, s_{n} \in\{-50,-25,25,50\}$, respectively, given $x_{t}^{a}=x_{t}^{b}=1$ and given $\mathcal{W}_{t-1}$ ? What is the probability of $y_{t}^{a}$ being equal to $s_{m} \in\{-50,-25,25,50\}$ when $y_{t}^{b}=0$ (no change for country $b$ occurs)? What is the probability of $y_{t}^{b}$ being equal to $s_{n} \in\{-50,-25,25,50\}$ when $y_{t}^{a}=0$ ?

Thus, starting from the bivariate normal distribution that characterizes $\left(\begin{array}{c}\widetilde{y}_{t}^{a} \\ \widetilde{y}_{t}^{b}\end{array}\right) \mid \mathcal{W}_{t-1}$, I want to retrieve $f\left(\widetilde{y}_{t}^{a}, \widetilde{y}_{t}^{b} \mid w_{t-1}, x_{t}^{a}, x_{t}^{b}\right)$. Conditional on $x_{t}^{a}$ and $x_{t}^{b}$, the bivariate normal density that characterizes the distributions of $\left(\varepsilon_{t}^{a}, \varepsilon_{t}^{b}\right)$ and $\left(\widetilde{y}_{t}^{a}, \widetilde{y}_{t}^{b}\right)$ is rewritten so as to redistribute the probability mass. Figure 3 contains a visual illustration of the necessary rescaling.

The log likelihood relative to the magnitude decision can be written as

$$
\mathcal{L}_{2}\left(\theta_{2}\right)=\sum_{t=1}^{T}\left\{\begin{array}{c}
1\left[x_{t}^{a}=1, x_{t}^{b}=0\right] \log P_{10} \\
+1\left[x_{t}^{a}=0, x_{t}^{b}=1\right] \log P_{01} \\
+1\left[x_{t}^{a}=1, x_{t}^{b}=1\right] \log P_{11}
\end{array}\right\}
$$

where $P_{10}$ denotes the probability of $y_{t}^{a}$ being equal to $s_{m} \in\{-50,-25,25,50\}$ when $y_{t}^{b}=0$ (no change for country $b$ occurs), once I have rescaled to condition on the timing decision $\left(x_{t}^{a}=1, x_{t}^{b}=0\right)$. A similar interpretation is given to $P_{01}$ and $P_{11} \cdot{ }^{10}$ A detailed derivation of these probabilities is presented in the appendix.

\section{Data}

The raw data that I use to analyze Fed and ECB decisions are the dates and size of changes in the FFTR and the MRO rate. Table 1 displays the FFTR level, dates on which it was changed, and the size of the change. Table 2 displays similar data for the Eurosystem. Dummies for FOMC and Governing Council meetings have also been included. Due to the youth of the EMU, my sample spans the period January $1^{\text {st }}, 1999$ to March 25 $5^{\text {th }}, 2005$ for a total of 325 weeks.

\footnotetext{
${ }^{10}$ Note that, given $x_{t}^{i}=0, i=a, b$, then $y^{i}=0$ with probability 1 . Thus $\log P_{00}=0$.
} 
As is clear from both table 1 and table 2, the Fed has changed rates more frequently than the ECB. The average duration for the US is about 89 days as opposed to 108 in the EMU. Figure 2 shows that there have been a total of 26 changes in the US and 15 in the EMU. In the US, nine were -50 bps changes, four were -25 bps changes, twelve were +25 bps changes, and one was a +50 bps change. In the EMU, five were -50 bps changes, three were -25 bps changes, five were +25 bps changes, and two were +50 bps changes.

Table 2 deserves a few comments. The first three dates refer to the period in which the market was adapting to the new system. In order to limit volatility, the corridor was narrowed from 250 basis points to 50 basis points on January $4^{\text {th }}, 1999$. On January $22^{\text {nd }}$, the corridor was set again at $250 \mathrm{bps}$, but since April $9^{\text {th }}$, it has been kept at $200 \mathrm{bps}$. Main refinancing operations which settled before June $28^{\text {th }}$, 2000 were conducted on the basis of fixed-rate tenders, in which the ECB would specify the interest rate in advance and participating counterparties would bid the amount of money (volume) they were willing to transact at that rate. A side effect of the system was chronic overbidding by financial institutions On June $8^{\text {th }}, 2000$, the ECB announced that, starting with the operation to be settled on June $28^{t h}$, 2000, the main refinancing operations would be conducted as variable-rate tenders, in which counterparties would specify both the amount and the interest rate at which they want to transact.

Together with these key policy rates, I create dummy variables to control for the FOMC schedule in the United States and the Governing Council schedule in the EMU. These dummies are important since the majority of interest rate changes happen on these scheduled meetings. The Fed has made three inter-meeting changes (January, April and September 2001), while the ECB has changed rates on a non-meeting day only once, in the immediate aftermath of September $11^{\text {th }}, 2001$.

Moreover, I construct a weekly real time data set. ${ }^{11}$ US variables include the CPI and GDP deflator as inflation measures, GDP growth, industrial production and the unemployment rate as output measures, and the euro/dollar exchange rate. EMU variables include the euro-zone $\mathrm{CPI}^{12}$ and GDP deflator as inflation measures, GDP growth, industrial production and the unemployment rate as output measures, and the euro/dollar exchange rate - see Table $3 .{ }^{13}$ I take weekly average exchange rate data. Notice that some of these variables are released at a frequency which is lower than weekly, and therefore the latest number can potentially be quite old and stale. This might explain why variables that are updated more frequently, such as

\footnotetext{
${ }^{11}$ The original data is available daily. That is, on a given day I observe whatever data is released, and for variables for which there is no release on that day, I consider the latest available number. To make this a weekly dataset, I am forced to cut off the information on Fridays prior to the meetings. For the ECB, Governing Council meetings are only on Thursdays, so I disregard all the information that arrives thereafter. FOMC meetings are normally held on Tuesdays, thus considering information until the Friday of the previous week is not very restrictive.

${ }^{12}$ Euro-zone inflation is measured by the Monetary Union Index of Consumer Prices (MUICP).

${ }^{13}$ Inflation and output variables, together with their released dates, are taken from Bloomberg.
} 
the CPI, IP and the unemployment rate, will be preferred to GDP and GDP deflator in the estimation results. Evans (2005) and Aruoba et al. (2006), among others, have focused on deriving daily or weekly estimates of GDP and other macroeconomic variables. Including those "sophisticated" variables might be a way to overcome this problem, but it goes beyond the scope of this paper.

The aim of collecting real-time data is to consider all the available information that the ECB and the Fed have at the beginning of week $t$. I am interested in knowing all estimates, provisional or final data released up until the end (Friday) of week $t-1$. In order to construct the Euro-zone GDP and CPI series, I make use of actual released data as well as flash estimates. Euro-zone $\mathrm{CPI}^{14}$ data for month $t$ are released in the second half of month $t+1$. The same release schedule also applies to the United States. CPI flash estimates represent a considerable enhancement in the available information because they are released within 5 to 10 days from the end of month $t$. Thus I include flash estimates as soon as they become available and substitute those with final data when they are released. Whereas in the United States GDP data for the quarter ending in month $t$ become available as early as the end of month $t+1$, in the euro area they used to become available at the beginning of month $t+3$. Flash estimates improve the available information because flash GDP estimates are now released as early as the middle of month $t+2$. Flash estimates for the CPI started being released in November 2001, for the October 2001 CPI. Flash estimates for GDP only began in May 2003, for 2003:Q1 GDP. ${ }^{15}$ Unemployment data relative to month $t$ are released in the first week of month $t+1$ in the United States and in the first week of month $t+2$ in the EMU.

I also construct two decision dummy variables that will be used to assess interdependence in timing decisions. The United States dummy variable takes the value one from the last EMU interest rate change until the first FOMC meeting. The EMU dummy variable takes the value one from the last US interest rate change until the second subsequent Governing Council meeting. The asymmetry comes from the fact that Governing Council meetings are more frequent than FOMC meetings (especially in the first part of the sample, when the Governing Council was meeting every two weeks; the FOMC meets only eight times a year), and I want to allow sufficient time for both central banks to react to policy changes.

\footnotetext{
${ }^{14}$ To compute the MUICP flash estimates, Eurostat uses early price information for the reference month from Member States for which data are available as well as early information about energy prices. The estimation procedure for the MUICP flash estimate combines historical information with partial information on price developments in the most recent months to give a total index for the euro-zone. No detailed breakdown is available.

${ }^{15}$ Thus I do not use flash estimates but only provisional and final estimates before those dates.
} 


\section{Estimation Strategy and Empirical Results}

\subsection{Bayesian Implementation ${ }^{16}$}

I conduct the estimation in a Bayesian framework. A Bayesian model is characterized by the probability distribution of the data, $p\left(Y^{T} \mid \theta\right)$, and by the prior distribution $p(\theta)$. I look at the probability of $\theta$ given the realized $Y^{T}$ :

$$
p\left(\theta \mid Y^{T}\right)=\frac{p\left(Y^{T} \mid \theta\right) p(\theta)}{\int p\left(Y^{T} \mid \theta\right) p(\theta) d \theta}
$$

so that the parameters $\theta$ are treated as random. Equation 24 simply shows how to recover the posterior distribution of $\theta$ by applying Bayes Theorem. The prior belief, which is chosen by the researcher based on economic considerations, can be thought of as an augmentation of the data set which is particularly useful when there are many parameters to be estimated from a short data sample. Bayesian analysis is therefore particularly well suited to my framework because it allows me to augment the data set by including pre-sample information, about the US and Germany, into the prior. ${ }^{17}$ ACD- and ACH-type models generally require fairly large data sets. ${ }^{18}$ Because of the youth of the ECB and the type of events I analyze, the data set is small. Bayesian estimation helps in this respect, although it does not completely eliminate the problem. ${ }^{19}$

I use the posterior odds test to select between models. Let $H_{0}$ be the null hypothesis with prior probability $\pi_{0,0}$. The posterior odds of $H_{0}$ versus $H_{1}$ are

$$
\frac{\pi_{0, T}}{\pi_{1, T}}=\left(\frac{\pi_{0,0}}{\pi_{1,0}}\right)\left(\frac{p\left(Y^{T} \mid H_{0}\right)}{p\left(Y^{T} \mid H_{1}\right)}\right)
$$

where $\left(\frac{p\left(Y^{T} \mid H_{0}\right)}{p\left(Y^{T} \mid H_{1}\right)}\right)$ is the Bayes factor containing the sample evidence and $p\left(Y^{T} \mid H_{i}\right)$ is the data density, which I approximate with a modified harmonic mean estimation. ${ }^{20}$

\footnotetext{
${ }^{16}$ I thank Frank Schorfheide for providing GAUSS code for the Bayesian estimation, which can be found at http://www.ssc.upenn.edu/ ${ }^{\sim}$ schorf/programs/gauss-bayesdsge.zip.

${ }^{17} \mathrm{I}$ use data on the German Bundesbank because it is the central bank in Europe that most closely resembles the ECB. Faust et al. (2001) study the monetary policy of the ECB and compare it with a simple empirical representation of the monetary policy of the Bundesbank before 1999.

${ }^{18}$ Omitted simulation results show that the BACH model, as well as all ACD and ACH type models, need a long data sample to identify the expected duration parameters $(\alpha$ and $\beta)$ and the constants.

${ }^{19}$ This data problem could have been avoided by analyzing the Fed and the Bank of Japan, or the Fed and the Bank of Canada. However, I believe that investigating the Fed and the ECB is more interesting.

${ }^{20}$ Interpretation of the posterior odds is as follows: $\pi_{0, T} / \pi_{1, T}>1$ null hypothesis is supported; $1>\pi_{0, T} / \pi_{1, T}>$ $10^{-1 / 2}$ evidence against $H_{0} ; 10^{-1 / 2}>\pi_{0, T} / \pi_{1, T}>10^{-1}$ substantial evidence against $H_{0} ; 10^{-1}>\pi_{0, T} / \pi_{1, T}>$ $10^{-3 / 2}$ strong evidence against $H_{0} ; 10^{-3 / 2}>\pi_{0, T} / \pi_{1, T}>10^{-2}$ very strong evidence against $H_{0} ; \pi_{0, T} / \pi_{1, T}<10^{-2}$
} 


\subsubsection{Choice of Priors}

I choose the priors for the parameters according to a number of considerations. I assume parameters are a priori independent of each other. Parameter restrictions are implemented by appropriately truncating the distribution or by redefining the parameters to be estimated.

Table 4 describes the distributional form, means and $90 \%$ confidence intervals of the BACH model priors. According to the Taylor rule literature, policy rates depend on their lagged values, on some measures of inflation and output deviations, and on exchange rate depreciation. Thus I assume that the probability of a rate change depends on the absolute deviation of inflation and output from a norm, and on the absolute exchange rate depreciation. I take absolute deviations because I want the probability of an interest rate change to increase with large deviations, regardless of their signs.

Let $R_{t}, \pi_{t}, y_{t}$ and $e r_{t}$ be, respectively, the interest rate, inflation rate, a measure of output growth, and nominal exchange rate depreciation. Also, let $\pi^{*}$ and $y^{*}$ be the optimal level of inflation and output growth, and $0<\rho^{R}<1$ be the smoothing term. Then we can write the Taylor rule as ${ }^{21}$

$$
\Delta R_{t}=\left(\rho^{R}-1\right) R_{t-1}+\left(1-\rho^{R}\right)\left[b_{1}\left(\pi_{t}-\pi^{*}\right)+b_{2}\left(y_{t}-y^{*}\right)+b_{3} e r_{t}\right]+\varepsilon_{t} .
$$

I should also include the lagged interest rate among the covariates. However, the duration in the model generates the dynamics that a lagged interest rate would normally generate. I will, however, verify that this is in fact the case. FOMC and Governing Council meeting dummies have also been included as covariates, following Hamilton and Jordà (2002).

I choose priors for $\alpha, \beta$ and the constant $w$ in equation 8 , so that the marginal hazard rate, when all the covariates are at their average value, ${ }^{22}$ matches the probability of an interest rate change over the ten-year pre-sample period January $1^{s t}$, 1989 to December $31^{s t}$, 1998. I approximate this probability by dividing the number of changes by the number of periods. Since I do not have any pre-sample data for the ECB, I use information about the German Lombard rate. I choose $\alpha, \beta$ and $w$ such that

$$
\begin{aligned}
h^{U S} & =\frac{1}{\alpha^{U S} \bar{u}^{U S}+\beta^{U S} \bar{\psi}^{U S}+w^{U S}}=\frac{39}{552}=0.07 \\
h^{E M U} & =\frac{1}{\alpha^{G} \bar{u}^{G}+\beta^{G} \bar{\psi}^{G}+w^{G}}=\frac{19}{552}=0.035
\end{aligned}
$$

where $\bar{u}$ and $\bar{\psi}$ represent the average values for duration and expected duration over the pre-

decisive evidence against $H_{0}$.

${ }^{21}$ See Lubik and Schorfheide.

${ }^{22} \mathrm{I}$ actually assume that $\pi^{*}$ and $y^{*}$ are the average inflation and output growth rates over the sample period. 
sample period 1989-1998. With this approach, of course, I cannot identify the three parameters involved in each equation. Thus I decide to fix $\alpha$ and $\beta$ to values close to those that have been estimated in the literature (see Hamilton and Jordà 2002 for US) and I vary $w$ to match the probability.

I choose priors for the covariates $z$ using the following relationships:

$$
\begin{aligned}
h^{U S} & =\frac{1}{\left\{\alpha^{U S} \bar{u}^{U S}+\beta^{U S} \bar{\psi}^{U S}+w^{U S}-\delta^{U S}\left|z^{U S}\right|\right\}} \\
h^{E M U} & =\frac{1}{\left\{\alpha^{G} \bar{u}^{G}+\beta^{G} \bar{\psi}^{G}+w^{G}-\delta^{E M U}\left|z^{E M U}\right|\right\}} .
\end{aligned}
$$

In particular, assuming all the other variables are at their average value, the prior for US inflation implies a 0.1 increase in the probability (from 0.07 to 0.17 ) when the inflation rate increases or decreases by 100 basis points. ${ }^{23}$ Similarly, the prior on the output growth implies that a 100 basis point change increases the probability by 0.04 . These probability changes might seem small compared to the Taylor rule coefficients that have been used in the literature. However, due to the non-linearity in the model, when taken together, they have a considerable effect. The asymmetry in treating inflation and output is justified by the fact that inflation always has a greater coefficient in the Taylor rule literature. Very similar priors are given to EMU inflation and output. The meeting dummy coefficients $\left(d^{i}, i=U S, E M U\right)$ are not treated equally in the two countries, due to the greater number of EMU meetings. Notice that, since I expect all the coefficients to be positive, ${ }^{24}$ I parameterized them as Gamma distributions.

I compute the mean of the odds ratio prior $(\eta)$ by using the pre-sample proportions for scenarios $(0,0),(0,1),(1,0)$ and $(1,1)$, over the period January $1^{\text {st }}, 1989$ to December $31^{\text {st }}, 1998$. Again, I use Germany instead of the EMU. The pre-sample odds ratio is about 5 .

I also choose priors for the Conditional Bivariate Ordered Probit based on pre-sample information. The means of the cut points are those that I would expect if I were to estimate an ordered Probit with no covariates, based on the data 1989-1998 for US and Germany. The first cut point $c_{1} \in R$, hence the Normal distribution. The other coefficients are appropriately redefined so as to guarantee that the cut points are ordered. Priors for US inflation and output coefficients are centered at values that have been commonly estimated for Taylor-type rules see equation 26 . Table 5 describes the distributional form, means and $90 \%$ confidence intervals of the priors of the CBO Probit model.

\footnotetext{
${ }^{23}$ For computational convenience the covariates data have been rescaled, so that 10 and 100 basis point changes read as 1 and 10 respectively.

${ }^{24}$ That is, I expect $-\delta<0$.
} 


\subsection{BACH Estimates}

I estimate a number of different specifications in order to asses which variables are in fact relevant for US and EMU timing decision. Table 3 shows the covariates I have considered. The basic specification I have selected includes meeting dummies, and inflation and unemployment absolute deviations. $^{25}$ Table 6 reports $90 \%$ posterior probabilities intervals and posterior means as point estimates. Figure 4 shows prior and posterior densities. As expected, the estimates confirm the need of a longer sample for ACD-type models, ${ }^{26}$ showing that the information contained in the data is not always adequate to significantly amend the prior. Duration and expected duration parameters $\left(\alpha^{i}\right.$ and $\left.\beta^{i}, i=U S, E M U\right)$, in particular, confirm this result. While tables 6 and 8 display means and posterior probability intervals for $\alpha$ and $\beta$, figure 4 exhibits their prior and posterior densities under a parameterization that shows the relevance of both coefficients in terms of duration persistence. ${ }^{27}$ The constant parameters for both the US and the EMU turn out to have a higher value compared to the prior means, possibly meaning a lower average probability over the sample. The increased value of the constant terms goes together with a smaller value for the coefficients of the other covariates. Nevertheless, the FOMC meeting dummy has a bigger coefficient than the Governing Council meeting dummy $(G C)$ : given that FOMC meetings are less frequent than Governing Council meetings, I expect a bigger increase in the probability of a rate change when the FOMC meets. For both countries inflation seems to play a bigger role than unemployment in determining the timing of a rate change.

An interesting by-product of the $\mathrm{BACH}$ model is that it generates persistence in the interest rate without including past interest rates. The basic specification with meeting dummies, inflation and output has been tested against a specification that also includes lagged interest rates, and the former has been selected. ${ }^{28}$ I have also tested for a specification that includes exchange rate data in the covariates. Once again the specification with meeting dummies, inflation and output has been favoured. ${ }^{29}$ Finally, unemployment is favoured over industrial production and GDP growth as a measure of output, and the CPI is preferred to the GDP deflator as a measure of inflation (results omitted).

\footnotetext{
${ }^{25}$ Thus unemployment and the CPI dominate GDP and GDP deflator measures. Intuitively, unemployment and the CPI are monthly statistics and therefore more promptly incorporate new information.

${ }^{26}$ Both the univariate Autoregressive Conditional Hazard $(\mathrm{ACH})$ model and the Bivariate Autoregressive Conditional Hazard $(\mathrm{BACH})$ require long data series to estimate ACD-type parameters $(\alpha$ and $\beta)$.

${ }^{27}$ Persistence is measured as $\alpha+\beta$.

${ }^{28}$ The marginal data density for the former is -160.3 , while for the latter is -165.45 .

${ }^{29}$ The marginal data density of the specification that includes meeting dummies, inflation, output and exchange rates is 162.57 .
} 


\subsection{Conditional Bivariate Ordered Probit Estimates}

The basic specification of the CBO Probit model that I estimate includes inflation, output and exchange rates. Table 7 reports $90 \%$ posterior probabilities intervals and posterior means as point estimates, figure 5 shows prior and posterior densities of the estimated parameters. Exchange rates do not play a very significant role. On the other hand, inflation and industrial production results exhibit interesting features. While inflation was a major factor in explaining US interest rate timing decisions, it is industrial production that seems to play the foremost role in explaining the size of changes in the US interest rate. Industrial production and inflation posterior means are, respectively 1.67 and 0.82. EMU magnitude results show that, as for the timing results, inflation is crucial and industrial production has a minor role. This is expected in view of the fact that the ECB primary objective is to maintain price stability; a policy of targeting output growth would probably be more problematic, given the intrinsic differences in the economies of the EMU countries. The correlation coefficient has a posterior mean of 0.28 , with a $90 \%$ interval equal to $[0.13,0.55]$.

\subsection{Interdependence}

The interdependence test of US and EMU timing decisions is twofold: on the one hand, I am interested in assessing "contemporaneous" interdependence, after controlling for each countries' macroeconomic conditions, which I refer to as synchronization; on the other hand I investigate the possibility of follower behaviors, after controlling for each countries' macroeconomic conditions. Assessing synchronization involves testing whether the odds ratio is different from 1 (1 meaning independence). The odds ratio indicates how much the odds of one country changing its target rate increase when the other country changes its target. Columns four and five in table 6 displays the estimation results for the independence setup. Setting the odds ratio to 1 does not significantly affect the other coefficients: both means and $90 \%$ probability intervals are very similar to the basic specification. However, as shown in table 9 , the posterior odds of the null hypothesis $H_{0}$ : odds ratio $=1$ versus the alternative, shows some evidence against the null. Thus the model seems to give some indication in favour of synchronization between the two target rates, after controlling for each countries' macroeconomic conditions. There was in fact a clear attempt at coordination after September $11^{\text {th }}$, 2001, episode after which both the Fed and the ECB lowered their target rates by 50 basis points.

Follower behaviors are studied by including the two decision dummies to account for the effect of the other country's decisions (see chapter 3 for a more detailed explanation of the dummy variables). Table 8 shows that estimation results are not affected significantly by including the two dummy variables. Table 9 suggests that the posterior odds ratio supports the null hypothesis of no follower behaviors. I obtain the same results by including only one dummy variable at a 
time. Table 9 displays the posterior odds ratio for these models.

I analyze interdependence in the CBO Probit framework by testing whether the correlation coefficient between the latent variables in equations (20) and (21) is different from zero. Table 7 presents the estimation results for this scenario. The posterior odds ratio in table 10 shows strong evidence against the model specification in which the correlation is set to zero. The correlation coefficient measures the correlation between the shocks ${ }^{30}$ in the unobservable variable equations - the omitted factors. The positive correlation seems to suggest that the interest rate feedback rules containing past interest rates, inflation, output, and the exchange rate might not capture the interdependence in the level decisions.

The BACH model with the odds ratio set to 1 and the CBO Probit Model with $\rho=1$ can be thought of as the Hamilton and Jordà (2002) univariate model estimated for both the Fed and the ECB. Please note that results for the US cannot be compared because the sample is different in term of length and included variables. Moreover Hamilton and Jordà (2002) do not use a real time data set.

\subsection{Omitting September 11th}

After the terrorist attack of September $11^{\text {th }}, 2001$, both the Fed and the ECB, as well as other central banks, lowered their target interest rates by 50 basis points on a non-meeting day, Monday September $17^{\text {th }}$, 2001. In my sample, the Fed has made three inter-meeting changes (January, April and September 2001), while the ECB has changed rates on a non-meeting day only in this particular occasion. Given the extraordinary nature of the event that triggered the September $17^{\text {th }}$ rate cuts, it makes sense to check for robustness of the results by excluding the September 2001 change, which simply represented a contemporaneous reaction to a common shock.

Results for the BACH model are displayed in table 11. All parameters have posterior means and $90 \%$ intervals very similar to those of the original data set (with 9/17). The odds ratio displays a lower value, as expected from removing the 9/17 episode. However, the posterior odds ratio still shows some evidence in favour of a model with positive dependence.

Results for the CBO Probit also suggest a lower correlation once we exclude the September 2001 inter-meeting change from the sample. However the model with positive correlation is still favoured to a model with zero correlation - see table 12 .

\footnotetext{
${ }^{30}$ By relating these shocks to the VAR literature, it turns out that, given the assumption that interest rates only depend on past values of output and inflation, the disturbances in equations (20) and (21) are purely monetary shocks.
} 


\section{A Vector Autoregression Comparison}

To check the goodness of fit of the model described in the paper, I compare it with a linear reduced form vector autoregression (VAR) of the form:

$$
\begin{aligned}
& x_{t}=B x_{t-1}+e_{t} \\
& e_{t} \sim\left(0, \Sigma_{e}\right)
\end{aligned}
$$

where $x_{t}$ and $e_{t}$ are $7 \times 1$ vectors, and the coefficient matrix $B$ is a $7 \times 7$ matrix. Our seven endogenous variables (let $M=7$ be the number of endogenous variables) include U.S. and Euro-zone policy rates $\left(r_{t}^{a}, r_{t}^{b}\right)$, inflation rates $\left(\pi_{t}^{a}, \pi_{t}^{b}\right)$, and output $\left(o_{t}^{a}, o_{t}^{b}\right)$, and the bilateral exchange rate depreciation $\left(\triangle E R_{t}\right){ }^{31}$

To make the VAR structure in (31) comparable to the BACH-CBO Probit model, an identification scheme that resembles the specification underlying the BACH-CBO Probit equations should be implemented. This would require the interest rate shock in country $b$ to affect the interest rate in country $a$ and vice versa, consistent with the assumption in the BACH Model that there could be some contemporaneous relation between the two interest rates. I also implement exclusion restrictions in the VAR in equation (31), so that it resembles closely the specification of the BACH and CBO Probit models. ${ }^{32}$ The reduced form that I estimate is:

$$
\begin{aligned}
r_{t}^{a} & =c_{1}+b_{1}^{\pi^{a}} \pi_{t-1}^{a}+b_{1}^{y^{a}} y_{t-1}^{a}+b_{1}^{r^{b}} r_{t-1}^{b}+b_{1}^{E R} \triangle E R_{t-1}+e_{t}^{1} \\
\pi_{t}^{a} & =c_{2}+b_{2}^{\pi^{a}} \pi_{t-1}^{a}+b_{2}^{y^{a}} y_{t-1}^{a}+b_{2}^{E R} \triangle E R_{t-1}+e_{t}^{2} \\
o_{t}^{a} & =c_{3}+b_{3}^{\pi^{a}} \pi_{t-1}^{a}+b_{3}^{y^{a}} y_{t-1}^{a}+b_{3}^{E R} \triangle E R_{t-1}+e_{t}^{3} \\
r_{t}^{b} & =c_{4}+b_{4}^{r^{a}} r_{t-1}^{a}+b_{4}^{\pi^{b}} \pi_{t-1}^{b}+b_{4}^{y^{b}} y_{t-1}^{b}+b_{4}^{E R} \triangle E R_{t-1}+e_{t}^{4} \\
\pi_{t}^{b} & =c_{5}+b_{5}^{\pi^{b}} \pi_{t-1}^{b}+b_{5}^{y^{b}} y_{t-1}^{b}+b_{5}^{E R} \triangle E R_{t-1}+e_{t}^{5} \\
o_{t}^{b} & =c_{6}+b_{6}^{\pi^{b}} \pi_{t-1}^{b}+b_{6}^{y^{b}} y_{t-1}^{b}+b_{6}^{E R} \triangle E R_{t-1}+e_{t}^{6} \\
\triangle E R_{t} & =c_{7}+b_{7}^{E R} \triangle E R_{t-1}+e_{t}^{7}
\end{aligned}
$$

That is, US (Euro-zone) inflation, US (Euro-zone) output, and the exchange rate are included in the US (Euro-zone) interest rate equation together with the other country's lagged interest rate. US (Euro-zone) inflation and output only depend on past values of US (Euro-zone) variables and on the exchange rate. The latter follows an $\mathrm{AR}(1)$ process.

The VAR model can be cast in the form of a seemingly unrelated regression equations (SURE)

\footnotetext{
${ }^{31}$ I use monthly data for the VAR. I use monthly averages of the effective Federal Funds rate and Eonia rate as interest rate variables. The bilateral exchange rate is also a monthly average.

${ }^{32}$ Hence, for example, I do not included lagged interest rates in the equations.
} 
model as

$$
\begin{aligned}
\underbrace{\left[\begin{array}{c}
\widetilde{x}^{1} \\
\widetilde{x}^{7}
\end{array}\right]}_{\widetilde{x}} & =\underbrace{\left[\begin{array}{ccc}
\widetilde{X}^{1} & & \\
& \ddots & \\
& & \widetilde{X}^{7}
\end{array}\right]}_{\widetilde{X}} \alpha+\underbrace{\left[\begin{array}{c}
\widetilde{\varepsilon}_{t}^{1} \\
\vdots \\
\widetilde{\varepsilon}_{t}^{7}
\end{array}\right]}_{\widetilde{\varepsilon}} \\
\widetilde{x} & =\widetilde{X} \alpha+\widetilde{\varepsilon} \\
\widetilde{\varepsilon} & \sim\left(0, \Sigma_{e} \otimes I_{T}\right)
\end{aligned}
$$

where the $\widetilde{x}^{i}, i=1, \ldots, 7$ denotes the $T$-dimensional endogenous variable vectors of observations, so that $\widetilde{x}$ is of dimension $T M \times 1 ; \widetilde{X}$ is of dimension $T M \times(M k+1)$ where $k$ is the number of non zero coefficients in $A$. $\widetilde{X}$ is a block diagonal matrix ${ }^{33}$, with $X^{i}, i=1, \ldots, 7$ of length $T$ containing the vectors of right-hand side variables with a non zero coefficient. ${ }^{34}$

Under the Litterman prior

$$
\varphi\left(\alpha, \Sigma_{\alpha}\right) \propto|\Sigma|^{-\frac{1}{2}} \exp \left\{-\frac{1}{2}(\alpha-\bar{\alpha})^{\prime} \bar{\Sigma}_{\alpha}^{-1}(\alpha-\bar{\alpha})\right\}
$$

the posterior densities are given by ${ }^{35}$

$$
\begin{aligned}
\alpha^{*} & =\Sigma_{\alpha^{*}}\left[\tilde{X}^{\prime}\left(\Sigma^{-1} \otimes I_{T}\right) \widetilde{x}+\bar{\Sigma}_{\alpha}^{-1} \bar{\alpha}\right] \\
\Sigma_{\alpha^{*}} & =\left[\left(\tilde{X}^{\prime} \Sigma_{e}^{-1} \otimes I_{T} \tilde{X}\right)+\bar{\Sigma}_{\alpha}^{-1}\right]^{-1} .
\end{aligned}
$$

I use the posterior odds $\frac{\pi_{0, T}}{\pi_{1, T}}=\left(\frac{\pi_{0,0}}{\pi_{1,0}}\right)\left(\frac{p\left(Y^{T} \mid M_{0}\right)}{p\left(Y^{T} \mid M_{1}\right)}\right)$ to compare the BACH-CBO Probit Models $\left(M_{0}\right)$ to the VAR specification $\left(M_{1}\right)$. As shown in table 13 the former outperforms the latter, suggesting that non linear dynamics might be important for understanding the evolution of policy rates.

\section{Conclusions}

In this paper I have derived and estimated with Bayesian techniques a bivariate model to account for interdependence between Fed and ECB decisions. I have operationalized interest rate timing decisions with a Bivariate Autoregressive Conditional Hazard (BACH) model and magnitude

\footnotetext{
${ }^{33}$ For ease of notation I do not include a constant term, but the estimated version also has a constant term in each equation.

${ }^{34}$ So for example $\widetilde{X}^{1}$, given our current specification, will be a $T \times 4$ matrix containing the $T$-dimensional vectors $r^{a} \pi^{a}, y^{a}$ and $\triangle E R$.

${ }^{35}$ See the appendix for the derivation.
} 
decisions with a Conditional Bivariate ordered (CBO) Probit model. The timing model yields evidence supporting the hypothesis that (i) institutional factors (scheduled FOMC and Governing Council meetings) and inflation rates are relevant variables for both central banks, (ii) output plays a minor role in timing decisions, and (iii) there exists synchronization but no follower behavior. The magnitude model illustrates that (i) inflation rates are the most important variables in determining interest rate levels, (ii) output plays a prime role for US magnitude decisions, and (iii) the posterior odds ratio favors a model with correlation in magnitude changes. I also find that, based on the posterior odds ratio, my model outperforms a linear VAR specification.

My findings are necessarily based on a relatively small sample; however, there seems to be evidence suggesting that timing and magnitude changes are in fact quite interesting issues. The paper provides evidence in favor of interaction in US and EMU interest rate timing and magnitude decisions, after controlling for traditional variables that have commonly been used in the literature. The paper offers a new methodology to analyze interdependence, however, it does not provide a complete answer to the underlying problem about what is in fact the source of the interdependence and whether interdependence is optimal. Identifying where the interdependence comes from and analyzing whether results are robust to the inclusion of a larger set of explanatory variables remain important topics for further research.

\section{References}

[1] Aruoba, S.B., Diebold, F.X. and Scotti, C., "Real-Time Estimate of Business Conditions," mimeo

[2] Bartolini, L. and Prati, A, 2003, "The Execution of Monetary Policy: A Tale of Two Central Banks," Economic Policy, 37, 437-467

[3] Bauwens L., Lubrano M. and Richard J.F., 1999, "Bayesian Inference in Dynamic Econometric Models," Oxford University Press, New York

[4] Benigno, P., 2002, "A Simple Approach to International Monetary Policy Coordination," Journal of International Economics, 57, 177-196

[5] Bergin, P.R. and Jordà, O., 2003, "Measuring Monetary Policy Interdependence," Journal of International Money and Finance, 23, 5

[6] Canova, F., forthcoming, "Methods for Applied Macroeconomic Research," Princeton University Press. 
[7] Cecchetti, S. and O'Sullivan, R., 2003, "The European Central Bank and the Federal Reserve," Oxford Review of Economic Policy, 19, 1

[8] Clarida, R., Galí, J., Gertler, M., 2002, "A simple framework for international monetary policy analysis," Journal of Monetary Economics 49, 879-904

[9] Cogley, T. and Sargent,T. J., 2002, "Evolving Post World War II U.S. Inflation Dynamics," NBER Macroeconomics Annual 16

[10] Corsetti, G., Pesenti, P ,2003, "The International dimension of optimal monetary policy," Journal of Monetary Economics, 52, 2, 281-305

[11] Engle, R., 2000, "The Econometrics of Ultra-High Frequency Data," Econometrica, 68, 1-22

[12] Engle, R. and Lunde, A., 2003, "Trades and Quotes: A Bivariate Point Process," Journal of Financial Econometrics, 1, 159-188

[13] Engle R.F. and Russel J., 1997, "Forecasting the Frequency of Changes in Quoted Foreign Exchange Prices with the Autoregressive Conditional Duration Model," J. Empirical Finance, 4, 187-212

[14] Engle R.F. and Russell J., 1998, "Autoregressive Conditional Duration: A New Model for Irregularly Spaced Transaction Data," Econometrica, 66, 1127-1162

[15] Engle R.F. and Russell J., 2005, "A Discrete-State Continuous-Time Model of Financial Transactions Prices: the ACM-ACD Model," Journal of Business and Economic Statisitcs

[16] Ehrmann, M. Fratzscher, M., 2003, "Monetary Policy Announcements and Money Markets: A Transatlantic Perspective," International Finance, 6, 309-28.

[17] Ehrmann, M. Fratzscher, M., 2005, "Equal size, equal role? Interest rate interdependence between the euro area and the United States," Economic Journal, 115, 930-950

[18] European Central Bank, 2002, "The Single Monetary Policy in the Euro Area. General Documentation on Eurosystem Monetary Policy Instruments and Procedures"

[19] Evans, C. L., 1998, "Real-Time Taylor Rules and the Federal Funds Futures Market," Federal Reserve Bank of Chicago Economic Perspectives (Third Quarter), 44-55

[20] Evans, M. D. D., 2005, "Where are we now? Real-Time Estimates of the Macro Economy," The International Journal of Central Banking, 1, 2, 127-175

[21] Faust, J., Rogers, J. H. and Wright, J.H., 2001, “An Empirical Comparison of Bundesbank and ECB Monetary Policy Rules", IFDP 705 
[22] Gaspar, V., Quiroz-Perez, G., Sicilia, J., 2001, "The ECB Monetary Policy Strategy and the Money Market," International Journal of Finance and Economics, 6, 4, 325-342

[23] Griffiths, W.,2003, "Bayesian Inference in the Seemingly Unrelated Regressions Model," in Computer-Aided Econometrics, David E. A. Giles, New York, Marcel Dekker

[24] Hamilton J.D. and Jordà O., 2002, "A Model for the Federal Reserve Rate Target," Journal of Political Economy, 110, 5, 1135-1167

[25] Hu, L. and Phillips, P., 2004, "Dynamics of Federal Funds Target Rate: a Nonstationary Discrete Choice Approach," Journal of Applied Econometrics, 19, 851-867.

[26] Lancaster, T., 1990, "The Econometrics Analysis of Transition Data," Cambridge University Press

[27] Lubik, T. and Schorfheide, F., 2003, "Do Central Banks Respond to Exchange Rates? A Structural Investigation," Journal of Monetary Economics, forthcoming

[28] Orphanides, A., 2001, "Monetary Rules Based on Real-Time Data," American Economic Review, 91, 4, 964-985

[29] Pappa, E., 2004, "Do the ECBand the fed really need to cooperate? Monetary Policy in a Two-Country World," Journal of Monetary Economics, 51, 4, 753-779

[30] Patton, A., 2005, "Modelling Asymmetric Exchange Rate Dependence," International Economic Review, forthcoming

[31] Piazzesi, M., 2005, "Bond Yields and the Federal Reserve," Journal of Political Economy, 113, 2, 311-344

[32] Russel, J., 1999, "Econometric Modeling of Multivariate Irregularly-Spaced High-Frequency Data," mimeo

[33] Schorfheide, F., 2000, "Loss Function-Based Evaluation of DSGE Models," Journal of Applied Econometrics, 15, 645-670

[34] Sims, C. and Zha, T., 1998, "Bayesian Methods for Dynamic Multivariate Models," International Economic Review, 39, 4, 949-968

[35] Tajar, A. Denuit, M. and Lambert, P. (2001) "Copula-type representation for random couples with Bernoulli margins," discussion paper 0118, Universite Catholique de Louvain

[36] Taylor, J., 1993, "Discretion versus policy rules in practice," Carnegie Rochester series on Public Policy 39, 195-214 
[37] Zhang, M, Russel, J., and Tsay, R., 2001, "A Nonlinear Conditional Autoregressive Duration Model with Applications to Financial Transactions Data," Journal of Econometrics, $104,1,179-207$

\section{Appendix}

\subsection{Fed and ECB}

The Federal Reserve System is composed of the Board of Governors and twelve Federal Reserve Banks. The Federal Open Market Committee (FOMC) is the policy-making organ of the Fed system, whose monetary policy decisions are carried out by the Federal Reserve Bank of New York. The Fed's policy tools are required reserve ratios, the discount rate and the Federal funds rate, which is influenced by open market operations. A detailed description of how the Fed system works can be found in Hamilton and Jordà (2002) and in Piazzesi (2005).

Open market operations are used much more frequently than the other two tools. Required reserve holdings have declined considerably in the past ten to fifteen years; the discount window has also had a very limited role in recent years.

When the Fed implements open market operations, it sells (buys) securities to (from) banks and debits (credits) the banks' account at the Fed. This implies an increase (decrease) in the amount of reserves held by banks at the Fed, and therefore will decrease (increase) the amount of reserves that they need to borrow from other banks in order to comply with reserve requirements. The rate at which banks borrow reserves from each other is the effective federal funds rate. When the FOMC sets the federal funds target rate, the New York Fed implements it through open market operations as described above. FOMC meetings are normally held eight times a year, or every five to eight weeks.

The European Central Bank (ECB), together with the national central banks of the European Monetary Union (EMU) Member States, constitutes the Eurosystem. The Euro-zone consisted of 11 member states up until 31st December 2000, and comprises 12 members since January 1st, 2001, when Greece joined. The Governing Council of the ECB formulates the monetary policy, the Executive Board implements this monetary policy and "to the extent deemed possible and appropriate and with a view to ensuring operational efficiency, the $E C B$ [has] recourse to the national central banks to carry out operations which form part of the tasks of the Eurosystem" (ECB 2002). 
The Eurosystem has the primary objective of maintaining price stability. Moreover "the Eurosystem has to support the general economic policies in the European Community" and, in order to attain these objectives, it "conducts open market operations, offers standing facilities and requires credit institutions to hold minimum reserves on accounts with the Eurosystem" (ECB 2002).

Open market operations are particularly important for signalling the stance of monetary policy, steering interest rates and controlling market liquidity. They are conducted through five types of instruments: reverse transactions (main instrument), outright transactions, issuance of debt certificates, foreign exchange swaps and collection of fixed-term deposits. Open market operations can be sorted in to four categories: main refinancing operations, longer-term refinancing operations, fine-tuning operations and structural operations.

The marginal lending facility and deposit facility are used, respectively, by national eligible institutions ${ }^{36}$ to obtain (overnight) liquidity from the national central banks and to make overnight deposits with national central banks at pre-specified interest rates. Those interest rates represent the ceiling and the floor for the overnight interest rate.

Moreover, the ECB requires credit institutions to hold minimum reserves on accounts with the national central banks. The double aim is to stabilize money market interest rates by giving institutions an incentive to smooth the effect of temporary liquidity fluctuations, and to improve the ability of the Eurosystem to function as a supplier of liquidity by generating or extending a liquidity shortage. Reserve requirements are determined on the basis of the end of calendar day balances over a one-month period (from the twenty-fourth day of a month to the twenty-third day of the next).

The key policy rate of the ECB is the rate applied to main refinancing operations (MRO). It has been either the minimum bid rate of variable rate tenders, or the rate applied to fixed rate tenders. The MRO rate has always been equal to the mid rate of the corridor set by the rates on the standing facilities. MROs are liquidity-providing repurchase transactions that supply the bulk of financing to the financial sector. They occur at a weekly frequency, have a two-week maturity, and are carried out by national central banks on the basis of standard tenders. The MRO rate is set by the Governing Council, which met on alternate Thursdays until October 2001. Since November 2001, interest rate decisions are discussed only during the meeting held on the first Thursday of the month. The Governing Council consists of all the members of the Executive Board and the governors of the national central banks of the Member States that have adopted the euro. The Executive Board consists of the President, the Vice-President, and four other members.

\footnotetext{
${ }^{36}$ Financially sound institutions that are subject to the minimum reserve requirement and that fulfill operational criteria satisfy these eligibility requirements. More information about eligible counterparties can be found in chapter 2 of ECB (2002).
} 


\subsection{CBO Probit Model}

The log likelihood relative to the magnitude decision is

$$
\mathcal{L}_{2}\left(\theta_{2}\right)=\sum_{t=1}^{T}\left\{\begin{array}{c}
1\left[x_{t}^{a}=1, x_{t}^{b}=0\right] \log P_{10} \\
+1\left[x_{t}^{a}=0, x_{t}^{b}=1\right] \log P_{01} \\
+1\left[x_{t}^{a}=1, x_{t}^{b}=1\right] \log P_{11}
\end{array}\right\}
$$

with

$$
\begin{aligned}
P_{10} & =\operatorname{Pr}\left(y_{t}^{a}=s_{m}, y_{t}^{b}=0 \mid w_{t-1}, x_{t}^{a}=1, x_{t}^{b}=0\right) \\
& =\operatorname{Pr}\left(c_{m-1}^{a}<\widetilde{y}_{t}^{a} \leq c_{m}^{a}, c_{2}^{b}<\widetilde{y}_{t}^{b} \leq c_{3}^{b} \mid w_{t-1}, x_{t}^{a}=1, x_{t}^{b}=0\right) \\
m & =1,2,4,5
\end{aligned}
$$

where the probability is computed using the density

$$
f\left(\widetilde{y}_{t}^{a}, \widetilde{y}_{t}^{b} \mid w_{t-1}, x_{t}^{a}=1, x_{t}^{b}=0\right)=\frac{f\left(\widetilde{y}_{t}^{a}, \widetilde{y}_{t}^{b} \mid w_{t-1}\right)}{\operatorname{Pr}\left\{\begin{array}{c}
{\left[\left(\widetilde{y}_{t}^{a} \leq c_{2}^{a}\right) \vee\left(\widetilde{y}_{t}^{a}>c_{3}^{a}\right)\right]} \\
\wedge\left(c_{2}^{b}<\widetilde{y}_{t}^{b} \leq c_{3}^{b}\right)
\end{array}\right\}}
$$

with

$$
\begin{aligned}
P_{01} & =\operatorname{Pr}\left(y_{t}^{a}=0, y_{t}^{b}=s_{n} \mid w_{t-1}, x_{t}^{a}=0, x_{t}^{b}=1\right) \\
& =\operatorname{Pr}\left(c_{2}^{a}<\widetilde{y}_{t}^{a} \leq c_{3}^{a}, c_{n-1}^{b}<\widetilde{y}_{t}^{b} \leq c_{n}^{b} \mid w_{t-1}, x_{t}^{a}=0, x_{t}^{b}=1\right) \\
n & =1,2,4,5
\end{aligned}
$$

where the probability is computed using the density

$$
f\left(\widetilde{y}_{t}^{a}, \widetilde{y}_{t}^{b} \mid w_{t-1}, x_{t}^{a}=0, x_{t}^{b}=1\right)=\frac{f\left(\widetilde{y}_{t}^{a}, \widetilde{y}_{t}^{b} \mid w_{t-1}\right)}{\operatorname{Pr}\left\{\begin{array}{c}
\left(c_{2}^{a}<\widetilde{y}_{t}^{a} \leq c_{3}^{a}\right) \\
\wedge\left[\left(\widetilde{y}_{t}^{b} \leq c_{2}^{b}\right) \vee\left(\widetilde{y}_{t}^{b}>c_{3}^{b}\right)\right]
\end{array}\right\}}
$$

and with

$$
\begin{aligned}
P_{11} & =\operatorname{Pr}\left(y_{t}^{a}=s_{m}, y_{t}^{b}=s_{n} \mid w_{t-1}, x_{t}^{a}=x_{t}^{b}=1\right) \\
& =\operatorname{Pr}\left(c_{m-1}^{a}<\widetilde{y}_{t}^{a} \leq c_{m}^{a}, c_{n-1}^{b}<\widetilde{y}_{t}^{b} \leq c_{n}^{b} \mid w_{t-1}, x_{t}^{a}=x_{t}^{b}=1\right) \\
m, n & =1,2,4,5
\end{aligned}
$$


where the probability is computed using the density

$$
f\left(\widetilde{y}_{t}^{a}, \widetilde{y}_{t}^{b} \mid w_{t-1}, x_{t}^{a}=x_{t}^{b}=1\right)=\frac{f\left(\widetilde{y}_{t}^{a}, \widetilde{y}_{t}^{b} \mid w_{t-1}\right)}{\operatorname{Pr}\left\{\begin{array}{c}
{\left[\left(\widetilde{y}_{t}^{a} \leq c_{2}^{a}\right) \vee\left(\widetilde{y}_{t}^{a}>c_{3}^{a}\right)\right]} \\
\wedge\left[\left(\widetilde{y}_{t}^{b} \leq c_{2}^{b}\right) \vee\left(\widetilde{y}_{t}^{b}>c_{3}^{b}\right)\right]
\end{array}\right\}} .
$$

\subsection{Bayesian Implementation}

Following Schorfheide (2000), I compute the mode $\widetilde{\theta}$ of the posterior density $p\left(\theta \mid Y^{T}\right)$ through a numerical optimization routine and then evaluate the inverse Hessian $\widetilde{\Sigma}$. I use a random walk Metropolis algorithm to generate $n_{\text {sim }}$ draws $\tilde{\theta}^{s}$ from the posterior $p\left(\theta \mid Y^{T}\right) .{ }^{37}$ At each iteration $s$, I draw a candidate parameter vector $\vartheta$ from a jumping distribution $J_{s}\left(\vartheta \mid \theta^{(s-1)}\right)$ and I accept the jump from $\theta^{(s-1)}$ so that $\theta^{(s)}=\vartheta$ with probability $\min (r, 1)$ where $r$ is defined as

$$
r=\frac{p\left(Y^{T} \mid \vartheta\right) p(\vartheta)}{p\left(Y^{T} \mid \theta^{(s-1)}\right) p\left(\theta^{(s-1)}\right)}
$$

and reject otherwise. The Markov chain sequence $\left\{\theta^{(s)}\right\}_{s=1}^{n_{s i m}}$ converges to the posterior distribution as $n_{\text {sim }} \rightarrow \infty$. I use a Gaussian jumping distribution $J_{s} \sim \mathcal{N}\left(\theta^{(s-1)}, c^{2} \widetilde{\Sigma}\right)$ with $c=0.3$.

\subsection{Posterior Densities}

Let $\theta=\left(\alpha, \Sigma_{\alpha}\right)$ represent the parameters and $y$ be the data. Consider the Litterman prior

$$
\varphi(\theta) \propto|\Sigma|^{-\frac{1}{2}} \exp \left\{(\alpha-\bar{\alpha})^{\prime} \bar{\Sigma}_{\alpha}^{-1}(\alpha-\bar{\alpha})\right\}
$$

and the SURE likelihood

$$
L(y \mid \theta) \propto|\Sigma|^{-\frac{T}{2}} \exp \left\{(\widetilde{x}-\tilde{X} \alpha)^{\prime}\left(\Sigma^{-1} \otimes I_{T}\right)(\widetilde{x}-\tilde{X} \alpha)\right\}^{\prime} .
$$

\footnotetext{
${ }^{37} \mathrm{I}$ use $n_{\text {sim }}=150,000$ for the BACH model and $n_{\text {sim }}=100,000$ for the CBO Probit Model.
} 
The argument of $\exp \{\bullet\}$ in equation $(47)$ can be rewritten as

$$
\begin{aligned}
& {\left[\left(\Sigma^{-1 / 2} \otimes I_{T}\right) \widetilde{x}-\Sigma^{-1 / 2} \otimes I_{T} \tilde{X} \alpha\right]^{\prime}\left[\left(\Sigma^{-1 / 2} \otimes I_{T}\right) \widetilde{x}-\Sigma^{-1 / 2} \otimes I_{T} \tilde{X} \alpha\right] } \\
&= {\left[\left(\Sigma^{-1 / 2} \otimes I_{T}\right) \widetilde{x}-\left(\Sigma^{-1 / 2} \otimes I_{T} \widetilde{X}\right) \underline{\alpha}\right]^{\prime}\left[\left(\Sigma^{-1 / 2} \otimes I_{T}\right) \widetilde{x}-\left(\Sigma^{-1 / 2} \otimes I_{T} \widetilde{X}\right) \underline{\alpha}\right] } \\
&+(\underline{\alpha}-\alpha)^{\prime} \underbrace{\left(\Sigma^{-1 / 2} \otimes I_{T} \widetilde{X}\right)^{\prime}\left(\Sigma^{-1 / 2} \otimes I_{T} \widetilde{X}\right)}_{\widetilde{X}^{\prime}\left(\Sigma^{-1} \otimes I_{T}\right) \widetilde{X}}(\underline{\alpha}-\alpha) \\
& \underline{\alpha}=\left[\widetilde{X}^{\prime}\left(\Sigma^{-1} \otimes I_{T}\right) \widetilde{X}\right]^{-1} \widetilde{X}^{\prime}\left(\Sigma^{-1} \otimes I_{T}\right) \widetilde{x}
\end{aligned}
$$

then

$$
\begin{aligned}
\varphi(\theta)(y \mid \theta) & \propto \exp \left\{(\alpha-\bar{\alpha})^{\prime} \bar{\Sigma}_{\alpha}^{-1}(\alpha-\bar{\alpha}) \times(\underline{\alpha}-\alpha)^{\prime}\left[\tilde{X}^{\prime}\left(\Sigma^{-1} \otimes I_{T}\right) \tilde{X}\right](\underline{\alpha}-\alpha)\right\} \\
& =\exp \left\{\left(\alpha-\alpha^{*}\right)^{\prime} \Sigma_{\alpha^{*}}^{-1}\left(\alpha-\alpha^{*}\right)\right\}
\end{aligned}
$$

with

$$
\begin{aligned}
\alpha^{*} & =\Sigma_{\alpha^{*}}\left[\tilde{X}^{\prime}\left(\Sigma^{-1} \otimes I_{T}\right) \widetilde{x}+\bar{\Sigma}_{\alpha}^{-1} \bar{\alpha}\right] \\
\Sigma_{\alpha^{*}} & =\left[\left(\widetilde{X}^{\prime} \Sigma_{e}^{-1} \otimes I_{T} \tilde{X}\right)+\bar{\Sigma}_{\alpha}^{-1}\right]^{-1} .
\end{aligned}
$$




\begin{tabular}{ccccc}
\hline \hline & FFTR & FFTR Change & Week Day & $\begin{array}{c}\text { Duration } \\
\text { in days }\end{array}$ \\
\hline 17-Nov-98 & 4.75 & & Tue & \\
30-Jun-99 & 5.00 & 0.25 & Wed & 225 \\
24-Aug-99 & 5.25 & 0.25 & Tue & 55 \\
16-Nov-99 & 5.50 & 0.25 & Tue & 84 \\
2-Feb-00 & 5.75 & 0.25 & Wed & 78 \\
21-Mar-00 & 6.00 & 0.25 & Tue & 48 \\
16-May-00 & 6.50 & 0.25 & Tue & 56 \\
03-Jan-01 & 6.00 & 0.50 & Wed & 232 \\
31-Jan-01 & 5.50 & -0.50 & Wed & 28 \\
20-Mar-01 & 5.00 & -0.50 & Tue & 48 \\
18-Apr-01 & 4.50 & -0.50 & Wed & 29 \\
15-May-01 & 4.00 & -0.50 & Tue & 27 \\
27-Jun-01 & 3.75 & -0.25 & Wed & 43 \\
21-Aug-01 & 3.50 & -0.25 & Tue & 55 \\
17-Sep-01 & 3.00 & -0.50 & Mon & 27 \\
2-Oct-01 & 2.50 & -0.50 & Tue & 15 \\
6-Nov-01 & 2.00 & -0.50 & Tue & 35 \\
11-Dec-01 & 1.75 & -0.25 & Tue & 35 \\
6-Nov-02 & 1.25 & -0.50 & Wed & 330 \\
25-Jun-03 & 1.00 & -0.25 & Wed & 231 \\
30-Jun-04 & 1.25 & 0.25 & Wed & 371 \\
10-Aug-04 & 1.50 & 0.25 & Tue & 41 \\
21-Sep-04 & 1.75 & 0.25 & Wed & 42 \\
10-Nov-04 & 2.00 & 0.25 & Wed & 50 \\
14-Dec-04 & 2.25 & 0.25 & Wed & 34 \\
02-Feb-05 & 2.50 & 0.25 & Wed & 50 \\
22-Mar-05 & 2.50 & 0.25 & Wed & 48 \\
\hline & & & & \\
\hline
\end{tabular}

Table 1: Calendar of Federal Funds Target Rate changes 


\begin{tabular}{|c|c|c|c|c|c|c|c|}
\hline & \multirow{2}{*}{$\begin{array}{l}\text { Deposit } \\
\text { Facility }\end{array}$} & \multicolumn{2}{|c|}{$\mathrm{MRO}$} & \multirow{2}{*}{$\begin{array}{l}\text { Marg. } \\
\text { Lending } \\
\text { Facility }\end{array}$} & \multirow{2}{*}{$\begin{array}{l}\text { MRO } \\
\text { change }\end{array}$} & \multirow{2}{*}{$\begin{array}{l}\text { Week } \\
\text { Day }\end{array}$} & \multirow{2}{*}{$\begin{array}{l}\text { Duration } \\
\text { in days }\end{array}$} \\
\hline & & $\underset{\text { Tender }}{\text { Fix.Rate }}$ & $\underset{\text { Tender }}{\text { Var. Rate }}$ & & & & \\
\hline 1-Jan-99 & 2.00 & 3 & - & 4.50 & & Fri & \\
\hline 4-Jan-99 & 2.75 & 3 & - & 3.25 & & Mon & \\
\hline 21-Jan-99 & 2.00 & 3 & - & 4.50 & & Thu & \\
\hline 8-Apr-99 & 1.50 & 2.5 & - & 3.50 & -0.50 & Thu & 97 \\
\hline 4-Nov-99 & 2.00 & 3 & - & 4.00 & 0.50 & Thu & 210 \\
\hline 3-Feb-00 & 2.25 & 3.25 & - & 4.25 & 0.25 & Thu & 91 \\
\hline 16-Mar-00 & 2.50 & 3.5 & - & 4.50 & 0.25 & Thu & 42 \\
\hline 27-Apr-00 & 2.75 & 3.75 & - & 4.75 & 0.25 & Thu & 42 \\
\hline 8-Jun-00 & 3.25 & 4.25 & - & 5.25 & 0.50 & Thu & 42 \\
\hline 28-Jun-00 & 3.25 & - & 4.25 & 5.25 & & Wed & \\
\hline 31-Aug-00 & 3.50 & - & 4.50 & 5.50 & 0.25 & Thu & 84 \\
\hline 05-Oct-00 & 3.75 & - & 4.75 & 5.75 & 0.25 & Thu & 35 \\
\hline 10-May-01 & 3.50 & - & 4.50 & 5.50 & -0.25 & Thu & 217 \\
\hline 30-Aug-01 & 3.25 & - & 4.25 & 5.25 & -0.25 & Thu & 112 \\
\hline 17-Sep-01 & 2.75 & - & 3.75 & 4.75 & -0.50 & Mon & 18 \\
\hline 8-Nov-01 & 2.25 & - & 3.25 & 4.25 & -0.50 & Thu & 52 \\
\hline 5-Dec-02 & 1.75 & - & 2.75 & 3.75 & -0.50 & Thu & 392 \\
\hline 6-Mar-03 & 1.50 & - & 2.50 & 3.50 & -0.25 & Thu & 91 \\
\hline 5-Jun-03 & 1.00 & - & 2.00 & 3.00 & -0.50 & Thu & 91 \\
\hline
\end{tabular}

Table 2: Calendar of Main Refinancing Operation rate changes

\begin{tabular}{|c|c|c|c|}
\hline US Variables & & \multicolumn{2}{|l|}{ EMU Variables } \\
\hline \multicolumn{4}{|c|}{ Meeting Dummies } \\
\hline FOMC & & \multicolumn{2}{|l|}{ Governing Council } \\
\hline \multicolumn{4}{|c|}{ Inflation Measures } \\
\hline CPI excl FE index & YOY\% & MUCPI & YOY\% \\
\hline GDP Deflator & YOY\% & GDP Deflator & YOY\% \\
\hline \multicolumn{4}{|c|}{ Output Measures } \\
\hline GDP Growth & YOY\% & GDP Growth & YOY\% \\
\hline Industrial Production & MOM\% & Industrial Production & МOM\% \\
\hline Unemployment Rate & & Unemployment Rate & \\
\hline \multicolumn{4}{|c|}{ Exchange Rate } \\
\hline Eurodollar Rate & Weekly Average & Eurodollar Rate & Weekly Average \\
\hline \multicolumn{4}{|c|}{ Decision Dummies } \\
\hline US decision & & EMU decision & \\
\hline
\end{tabular}

Table 3: Explanatory variables included in the dataset 


\begin{tabular}{lccccc}
\hline \hline \multicolumn{7}{c}{ BACH Model - Prior Distribution } \\
Parameter & Range & Density & Mean & St. Dev. & $90 \%$ Interval \\
\hline$\alpha^{U S}$ & {$[0,1)$} & Beta & 0.16 & 0.09 & {$[0.02,0.29]$} \\
$\beta^{U S}$ & {$[0,1)$} & Beta & 0.64 & 0.15 & {$[0.41,0.88]$} \\
$w^{U S}$ & $R^{+}$ & Gamma & 12.00 & 4.98 & {$[4.24,19.62]$} \\
$F O M C$ & $R^{+}$ & Gamma & 6.00 & 1.50 & {$[3.55,8.40]$} \\
$C P I^{U S}$ & $R^{+}$ & Gamma & 0.80 & 0.50 & {$[0.08,1.50]$} \\
$-U^{U S}$ & $R^{+}$ & Gamma & 0.60 & 0.70 & {$[0.00,1.50]$} \\
$d^{U S}$ & $R^{+}$ & Gamma & 2.00 & 1.00 & {$[0.49,3.48]$} \\
$\alpha^{E M U}$ & {$[0,1)$} & Beta & 0.14 & 0.08 & {$[0.02,0.25]$} \\
$\beta^{E M U}$ & {$[0,1)$} & Beta & 0.56 & 0.14 & {$[0.34,0.80]$} \\
$w^{E M U}$ & $R^{+}$ & Gamma & 15.00 & 4.98 & {$[7.83,23.56]$} \\
$G C$ & $R^{+}$ & Gamma & 4.99 & 1.50 & {$[2.50,7.29]$} \\
$C P I^{E M U}$ & $R^{+}$ & Gamma & 0.80 & 0.40 & {$[0.19,1.38]$} \\
$-U^{E M U}$ & $R^{+}$ & Gamma & 0.60 & 0.40 & {$[0.04,1.15]$} \\
$d^{E M U}$ & $R^{+}$ & Gamma & 2.00 & 1.00 & {$[0.47,3.46]$} \\
$\eta$ & $R^{+}$ & Gamma & 5.00 & 3.00 & {$[0.61,9.23]$} \\
\hline
\end{tabular}

Table 4: The table reports information on the $\mathrm{BACH}$ parameter priors

\begin{tabular}{lccccc}
\hline \hline \multicolumn{5}{c}{ CBO Probit Model-Prior Distribution } \\
\multicolumn{1}{c}{ Parameter } & Range & Density & Mean & St.Dev. & $90 \%$ Interval \\
\hline$c_{1}^{U S}$ & $R$ & Normal & -2.15 & 2.00 & {$[-7.00,2.85]$} \\
$c_{2}^{U S}-c_{1}^{U S}$ & $R^{+}$ & Gamma & 0.70 & 1.98 & {$[0.00,1.99]$} \\
$c_{3}^{U S}-c_{2}^{U S}$ & $R^{+}$ & Gamma & 3.11 & 1.99 & {$[0.30,5.90]$} \\
$c_{4}^{U S}-c_{3}^{U S}$ & $R^{+}$ & Gamma & 0.67 & 2.00 & {$[0.00,1.83]$} \\
$C P I^{U S}$ & $R^{+}$ & Gamma & 1.54 & 0.50 & {$[0.74,2.32]$} \\
$I P^{U S}$ & $R^{+}$ & Gamma & 0.25 & 0.40 & {$[0.00,0.71]$} \\
$\Delta e r_{t}^{U S}$ & $R^{+}$ & Gamma & 0.25 & 0.20 & {$[0.00,0.51]$} \\
$c_{1}^{E M U}$ & $R$ & Normal & -2.15 & 2.00 & {$[-7.17,2.76]$} \\
$c_{2}^{E M U}-c_{1}^{E M U}$ & $R^{+}$ & Gamma & 0.92 & 2.01 & {$[0.00,2.78]$} \\
$c_{3}^{E M U}-c_{2}^{E M U}$ & $R^{+}$ & Gamma & 4.28 & 2.00 & {$[1.13,7.23]$} \\
$c_{4}^{E M U}-c_{3}^{E M U}$ & $R^{+}$ & Gamma & 0.81 & 1.97 & {$[0.00,2.46]$} \\
$C P I^{E M U}$ & $R^{+}$ & Gamma & 1.54 & 0.50 & {$[0.74,2.33]$} \\
$I P^{E M U}$ & $R^{+}$ & Gamma & 0.25 & 0.20 & {$[0.00,0.52]$} \\
$\Delta e r_{t}^{U E M U}$ & $R^{+}$ & Gamma & 0.25 & 0.20 & {$[0.00,0.52]$} \\
$\rho$ & {$[-1,1]$} & Normal & 0.00 & 0.40 & {$[-0.66,0.65]$} \\
\hline
\end{tabular}

Table 5: The table reports information on the CBO Probit parameter priors 


\begin{tabular}{lcccc}
\hline \hline \multicolumn{4}{c}{ BACH Parameter Estimation Results } \\
Parameter & Mean & $90 \%$ Interval & Mean & $90 \%$ Interval \\
\hline$\alpha^{U S}$ & 0.12 & {$[0.02,0.23]$} & 0.12 & {$[0.02,0.22]$} \\
$\beta^{U S}$ & 0.62 & {$[0.36,0.88]$} & 0.58 & {$[0.30,0.87]$} \\
$w^{U S}$ & 16.55 & {$[10.71,22.02]$} & 16.58 & {$[10.92,22.49]$} \\
$F O M C$ & 4.83 & {$[2.95,6.69]$} & 4.80 & {$[2.89,6.62]$} \\
$C P I^{U S}$ & 0.49 & {$[0.07,0.88]$} & 0.50 & {$[0.06,0.90]$} \\
$-U^{U S}$ & 0.16 & {$[0.00,0.39]$} & 0.13 & {$[0.00,0.32]$} \\
$d^{U S}$ & - & - & - & - \\
$\alpha^{E M U}$ & 0.18 & {$[0.04,0.30]$} & 0.18 & {$[0.04,0.30]$} \\
$\beta^{E M U}$ & 0.60 & {$[0.38,0.80]$} & 0.60 & {$[0.39,0.87]$} \\
$w^{E M U}$ & 21.62 & {$[13.86,29.06]$} & 21.46 & {$[13.92,29.17]$} \\
$G C$ & 4.19 & {$[2.15,6.10]$} & 4.21 & {$[2.18,6.23]$} \\
$C P I^{E M U}$ & 0.52 & {$[0.13,0.87]$} & 0.53 & {$[0.15,0.89]$} \\
$-U^{E M U}$ & 0.28 & {$[0.04,0.51]$} & 0.28 & {$[0.04,0.51]$} \\
$d^{E M U}$ & - & - & - & - \\
$\eta$ & 3.74 & {$[1.17,6.16]$} & 1 & - \\
\hline
\end{tabular}

Table 6: BACH model posterior means and intervals for (i) the basic specification and (ii) the specification with the odds ratio fixed at its independence value (odds ratio $=1$ )

\begin{tabular}{lcccc}
\hline \hline \multicolumn{5}{c}{ CBO Probit Parameter Estimation Results } \\
& \multicolumn{2}{c}{ Basic Model } & & $\rho=0$ \\
\multicolumn{1}{c}{ Parameter } & Mean & $90 \%$ Interval & Mean & $90 \%$ Interval \\
\hline$c_{1}^{U S}$ & 0.17 & {$[-1.30,1.76]$} & 0.17 & {$[-1.10,1.47]$} \\
$c_{2}^{U S}-c_{1}^{U S}$ & 0.29 & {$[0.05,0.52]$} & 0.31 & {$[0.05,0.57]$} \\
$c_{3}^{U S}-c_{2}^{U S}$ & 2.42 & {$[0.42,4.26]$} & 2.11 & {$[0.40,3.75]$} \\
$c_{4}^{U S}-c_{3}^{U S}$ & 1.73 & {$[0.61,2.76]$} & 1.94 & {$[0.75,3.07]$} \\
$C P I^{U S}$ & 0.82 & {$[0.35,0.81]$} & 0.77 & {$[0.40,1.14]$} \\
$I P^{U S}$ & 1.67 & {$[0.56,1.6]$} & 1.87 & {$[1.03,2.70]$} \\
$\Delta e r_{t}^{U S}$ & 0.16 & {$[0.00,0.26]$} & 0.14 & {$[0.00,0.27]$} \\
$c_{1}^{E M U}$ & 0.45 & {$[-0.93,1.87]$} & 0.72 & {$[-0.67,2.08]$} \\
$c_{2}^{E M U}-c_{1}^{E M U}$ & 0.34 & {$[0.05,0.63]$} & 0.38 & {$[0.06,0.70]$} \\
$c_{3}^{E M U}-c_{2}^{E M U}$ & 2.86 & {$[0.92,4.77]$} & 2.41 & {$[0.80,4.03]$} \\
$c_{4}^{E M U}-c_{3}^{E M U}$ & 0.66 & {$[0.19,1.13]$} & 0.73 & {$[0.21,1.23]$} \\
$C P I^{E M U}$ & 0.64 & {$[0.33,0.97]$} & 0.65 & {$[0.31,0.96]$} \\
$I P^{E M U}$ & 0.36 & {$[0.15,0.57]$} & 0.35 & {$[0.15,0.55]$} \\
$\Delta e r_{t}^{U E M U}$ & 0.11 & {$[0.00,0.23]$} & 0.11 & {$[0.00,0.22]$} \\
$\rho$ & 0.28 & {$[0.13,0.55]$} & 0 & - \\
\hline
\end{tabular}

Table 7: CBO Probit model posterior means and intervals for (i) the basic specification and for (ii) the specification with the correlation coefficient fixed to zero 


\begin{tabular}{ccccccc}
\hline \hline \multicolumn{7}{c}{ BACH Parameter Estimation Results } \\
& \multicolumn{2}{c}{ EMU Follower } & \multicolumn{2}{c}{ US Follower } & \multicolumn{2}{c}{ Both Dummies } \\
Parameter & Mean & $90 \%$ Interval & Mean & $90 \%$ Interval & Mean & $90 \%$ Interval \\
\hline$\alpha^{U S}$ & 0.12 & {$[0.02,0.23]$} & 0.12 & {$[0.01,0.22]$} & 0.13 & {$[0.02,0.24]$} \\
$\beta^{U S}$ & 0.59 & {$[0.33,0.87]$} & 0.61 & {$[0.35,0.89]$} & 0.58 & {$[0.31,0.85]$} \\
$w^{U S}$ & 16.20 & {$[10.64,21.75]$} & 17.10 & {$[11.49,22.96]$} & 17.05 & {$[11.24,22.61]$} \\
$F O M C$ & 4.72 & {$[2.84,6.44]$} & 4.72 & {$[2.92,6.66]$} & 4.69 & {$[2.84,6.53]$} \\
$C P I^{U S}$ & 0.49 & {$[0.07,0.88]$} & 0.49 & {$[0.08,0.88]$} & 0.48 & {$[0.07,0.86]$} \\
$-U^{U S}$ & 0.11 & {$[0.00,0.25]$} & 0.15 & {$[0.00,0.35]$} & 0.15 & {$[0.00,0.38]$} \\
$d^{U S}$ & - & - & 1.91 & {$[0.47,3.33]$} & 1.93 & {$[0.44,3.32]$} \\
$\alpha^{E M U}$ & 0.18 & {$[0.04,0.30]$} & 0.18 & {$[0.05,0.31]$} & 0.19 & {$[0.05,0.32]$} \\
$\beta^{E M U}$ & 0.60 & {$[0.39,0.82]$} & 0.61 & {$[0.40,0.82]$} & 0.62 & {$[0.41,0.82]$} \\
$w^{E M U}$ & 21.94 & {$[14.41,29.95]$} & 21.78 & {$[13.86,29.04]$} & 22.10 & {$[14.49,29.99]$} \\
$G C$ & 4.20 & {$[2.18,6.10]$} & 4.18 & {$[2.19,6.21]$} & 4.14 & {$[2.18,6.06]$} \\
$C P I^{E M U}$ & 0.51 & {$[0.14,0.88]$} & 0.54 & {$[0.15,0.91]$} & 0.52 & {$[0.15,0.91]$} \\
$-U^{E M U}$ & 0.28 & {$[0.04,0.51]$} & 0.28 & {$[0.04,0.51]$} & 0.29 & {$[0.04,0.53]$} \\
$d^{E M U}$ & 1.89 & {$[0.48,3.28]$} & - & - & 1.85 & {$[0.46,3.26]$} \\
$\eta$ & 3.74 & {$[1.11,6.31]$} & 3.84 & {$[1.12,6.26]$} & 3.90 & {$[1.16,6.36]$} \\
\hline
\end{tabular}

Table 8: BACH model posterior means and intervals for (i) the specification with the US dummy variable in the EMU decision variables (EMU follower), (ii) the specification with the EMU dummy variable in the US decision variables (US follower), and (iii) the specification with both dummy variables

\begin{tabular}{lcc}
\hline \hline & Marginal Data Densities & Posterior Odds \\
\cline { 2 - 3 } & & \\
Basic Model & -160.3 & \\
No Synchronization $(\eta=1)$ & -160.83 & 0.58 \\
US Leader / EMU Follower & & $\left(H_{1}:\right.$ Basic Model $)$ \\
1.53 \\
EMU Leader / US Follower & -160.72 & $\left(H_{0}:\right.$ Basic Model $)$ \\
1.00 \\
Both US and EMU Dummies & -160.3 & $\left(H_{0}:\right.$ Basic Model $)$ \\
& -160.53 & $\left(H_{0}:\right.$ Basic Model $)$ \\
\hline
\end{tabular}

Table 9: BACH Model posterior odds for the synchronization and the leader/ follower models

\begin{tabular}{lcc}
\hline \hline & Marginal Data Densities & Posterior Odds \\
\cline { 2 - 3 } Basic Model & -66.11 & \\
$\rho=0$ & -66.62 & 0.60 \\
& & $\left(H_{0}: \rho=0\right)$ \\
\hline
\end{tabular}

Table 10: CBO Probit Model posterior odds for the correlation in magnitude hypothesis 


\begin{tabular}{|c|c|c|c|c|}
\hline \multicolumn{5}{|c|}{ "BACH Parameter Estimation Results - Excl. 9/11 } \\
\hline & \multicolumn{2}{|c|}{ Basic Specification } & \multicolumn{2}{|c|}{ No- Synchronization } \\
\hline Parameter & Mean & $90 \%$ Interval & Mean & $90 \%$ Interval \\
\hline$\alpha^{U S}$ & 0.13 & $0.02,0.24$ & 0.12 & $0.02,0.23$ \\
\hline$\beta^{U S}$ & 0.63 & $0.37,0.90$ & 0.61 & $0.36,0.88$ \\
\hline$w^{U S}$ & 16.67 & $10.85,22.75$ & 16.68 & $10.69,22.42$ \\
\hline$F O M C$ & 4.92 & $2.94,6.85$ & 4.92 & $3.03,6.78$ \\
\hline$C P I^{U S}$ & 0.48 & $0.08,0.87$ & 0.48 & $0.07,0.88$ \\
\hline$-U^{U S}$ & 0.16 & $0.00,0.42$ & 0.16 & $0.00,0.39$ \\
\hline$\alpha^{E M U}$ & 0.19 & $0.05,0.33$ & 0.19 & $0.04,0.31$ \\
\hline$\beta^{E M U}$ & 0.60 & $0.39,0.81$ & 0.60 & $0.40,0.88$ \\
\hline$w^{E M U}$ & 21.70 & $13.45,29.73$ & 21.48 & $13.65,29.10$ \\
\hline$G C$ & 4.16 & {$[2.15,6.10$} & 4.20 & $2.14,6.18]$ \\
\hline$C P I^{E M U}$ & 0.51 & $0.14,0.86$ & 0.53 & $0.13,0.88$ \\
\hline$-U^{E M U}$ & 0.30 & $0.03,0.55$ & 0.28 & $0.03,0.52]$ \\
\hline$\eta$ & 3.49 & $1.03,5.82$ & 1 & - \\
\hline \multicolumn{5}{|c|}{ Marginal Data Densities } \\
\hline & & -155.30 & & -155.01 \\
\hline \multicolumn{3}{|c|}{ Posterior Odds $\left(H_{0}: \eta=1\right)$} & \multicolumn{2}{|r|}{0.75} \\
\hline
\end{tabular}

Table 11: BACH model posterior means and intervals for the basic specification in which the September 2001 inter-meeting change has been removed 


\begin{tabular}{|c|c|c|c|c|}
\hline \multirow{2}{*}{$\begin{array}{l}\text { CBO Probit } \\
\text { Parameter }\end{array}$} & \multicolumn{2}{|c|}{$\begin{array}{c}\text { Parameter Estimation } \\
\text { Basic Model }\end{array}$} & \multicolumn{2}{|c|}{$\begin{array}{c}\text { Results - Excl. 9/11 } \\
\rho=0\end{array}$} \\
\hline & Mean & $90 \%$ Interval & Mean & $90 \%$ Interval \\
\hline$c_{1}^{U S}$ & 0.21 & {$[-1.21,1.64]$} & 0.18 & {$[-1.12,1.49]$} \\
\hline$c_{2}^{U S}-c_{1}^{U S}$ & 0.30 & {$[0.06,0.54]$} & 0.33 & {$[0.06,0.58]$} \\
\hline$c_{3}^{U S}-c_{2}^{U S}$ & 2.23 & {$[0.40,3.91]$} & 2.06 & {$[0.34,3.56]$} \\
\hline$c_{4}^{U S}-c_{3}^{U S}$ & 1.86 & {$[0.72,2.88]$} & 1.92 & {$[0.82,3.03]$} \\
\hline$C P I^{U S}$ & 0.83 & {$[0.41,1.24]$} & 0.77 & {$[0.38,1.15]$} \\
\hline$I P^{U S}$ & 1.70 & {$[0.85,2.50]$} & 1.83 & {$[0.99,2.67]$} \\
\hline$\Delta e r_{t}^{U S}$ & 0.14 & {$[0.00,0.28]$} & 0.16 & {$[0.00,0.32]$} \\
\hline$c_{1}^{E M U}$ & 0.46 & {$[-0.90,1.83]$} & 0.57 & {$[-0.77,1.91]$} \\
\hline$c_{2}^{E M U}-c_{1}^{E M U}$ & 0.39 & {$[0.05,0.73]$} & 0.44 & {$[0.07,0.81]$} \\
\hline$c_{3}^{E M U}-c_{2}^{E M U}$ & 2.70 & {$[0.87,4.42]$} & 2.40 & {$[0.82,3.93]$} \\
\hline$c_{4}^{E M U}-c_{3}^{E M U}$ & 0.67 & {$[0.18,1.14]$} & 0.76 & {$[0.23,1.26]$} \\
\hline$C P I^{E M U^{\circ}}$ & 0.69 & {$[0.34,1.03]$} & 0.68 & {$[0.33,1.02]$} \\
\hline$I P^{E M U}$ & 0.34 & {$[0.13,0.54]$} & 0.33 & {$[0.13,0.53]$} \\
\hline$\Delta e r_{t}^{U E M U}$ & 0.15 & {$[0.00,0.31]$} & 0.13 & {$[0.00,0.26]$} \\
\hline$\rho$ & 0.25 & {$[-0.02,0.54]$} & 0 & - \\
\hline
\end{tabular}

Marginal Data Densities

Posterior Odds $\left(H_{0}: \rho=0\right)$

0.81

Table 12: CBO Probit model posterior means and intervals for the basic specification in which the September 2001 inter-meeting change has been removed

\begin{tabular}{lcc}
\hline \hline & Marginal Data Densities & Posterior Odds \\
\cline { 2 - 3 } BACH-CBO Probit $\left(M_{0}\right)$ & -226.41 & \\
VAR $\left(M_{1}\right)$ & -228.82 & 11.3 \\
\hline
\end{tabular}

Table 13: VAR Comparison: posterior odds 


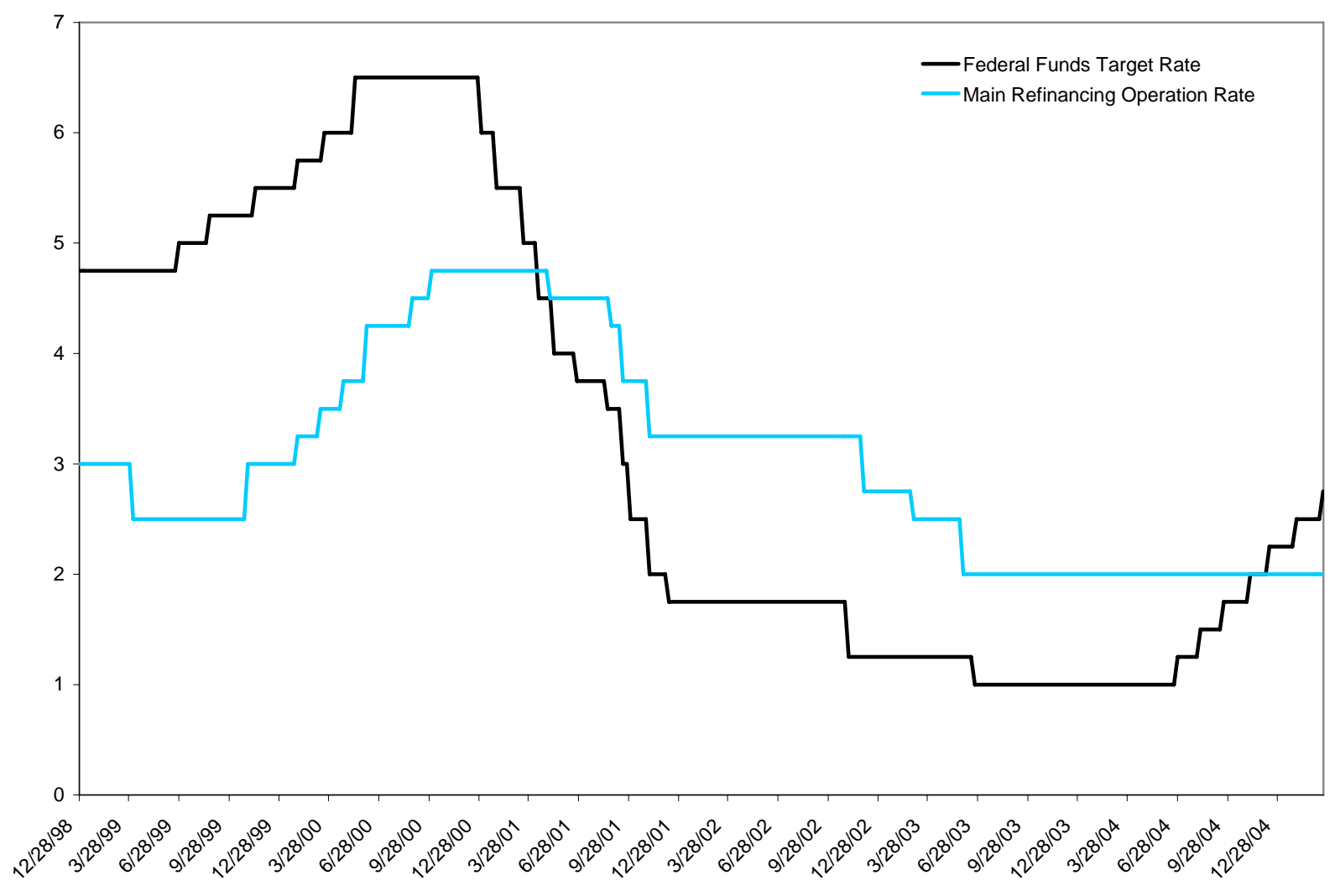

Figure 1: Evolution of the Federal Funds Target Rate (FFTR) and of the Main Refinancing Operation (MRO) rate from the beginning of 1999 until March 25th, 2005 


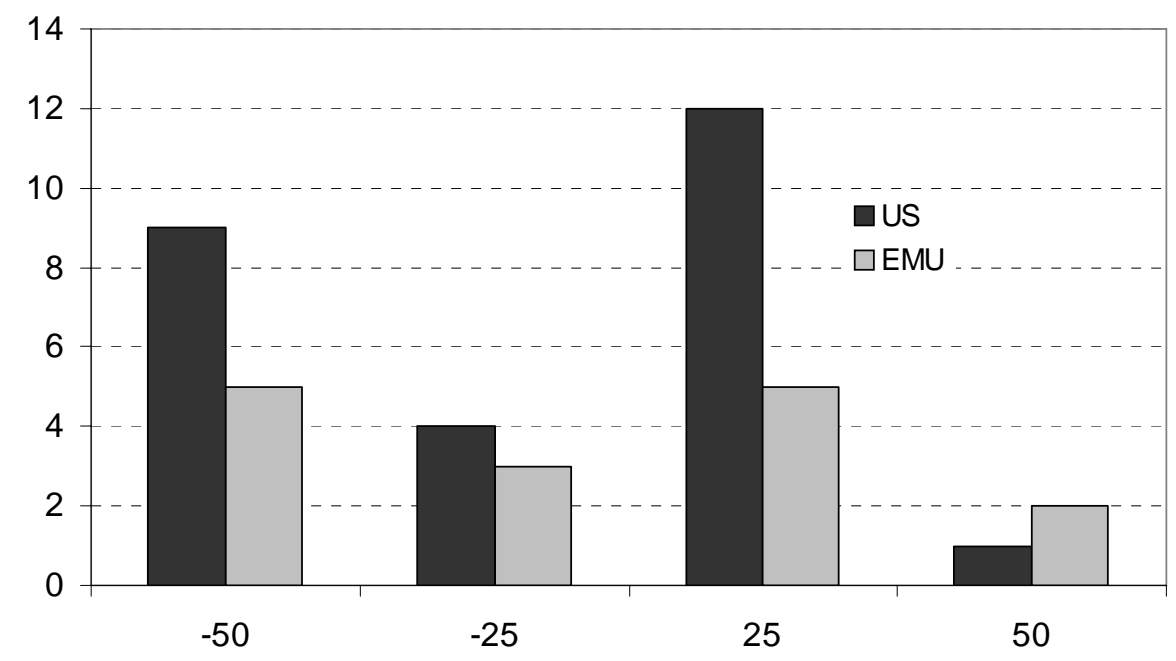

Figure 2: Basis point change distribution in the US and in the EMU 

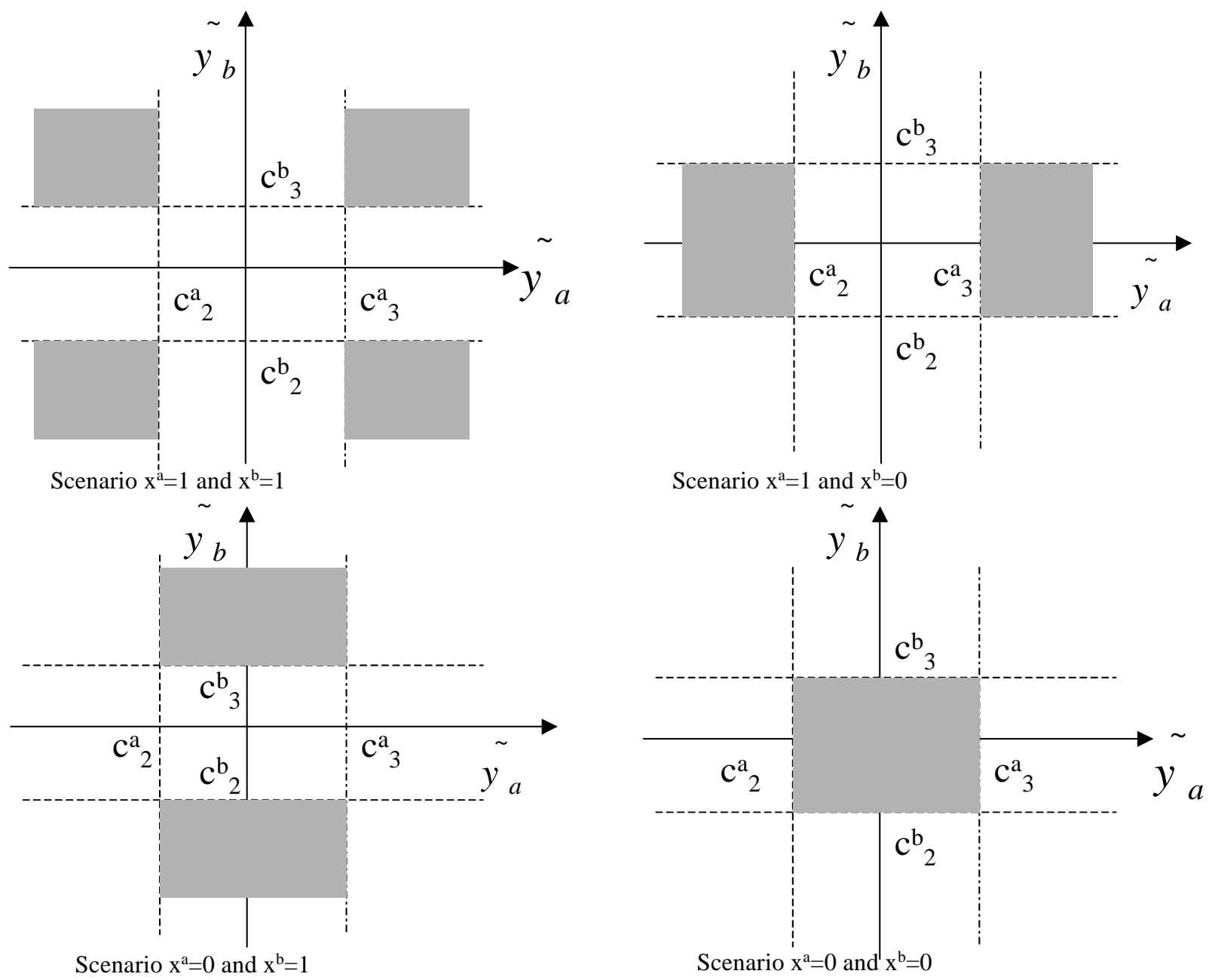

Figure 3: The above panels show the rescaling necessary to condition on $\left(x_{t}^{a}, x_{t}^{b}\right)$. In particular, the shaded areas of the top left panel show the feasible regions for $\left(y_{t}^{a}, y_{t}^{b}\right)$ when $\left(x_{t}^{a}=1, x_{t}^{b}=1\right)$; the top right panel shows the feasible region for $y^{a}$ when $\left(x_{t}^{a}=1, x_{t}^{b}=0\right)$, in which case $y^{b}=0$ with probability 1 ; the bottom left panel shows the feasible region for $y^{b}$ when $\left(x_{t}^{a}=0, x_{t}^{b}=1\right)$, in which case $y^{a}=0$ with probability 1 ; and the bottom right panel shows the feasible region when $\left(x_{t}^{a}=0, x_{t}^{b}=0\right)$, in which case $y^{a}=y^{b}=0$ with probability 1 

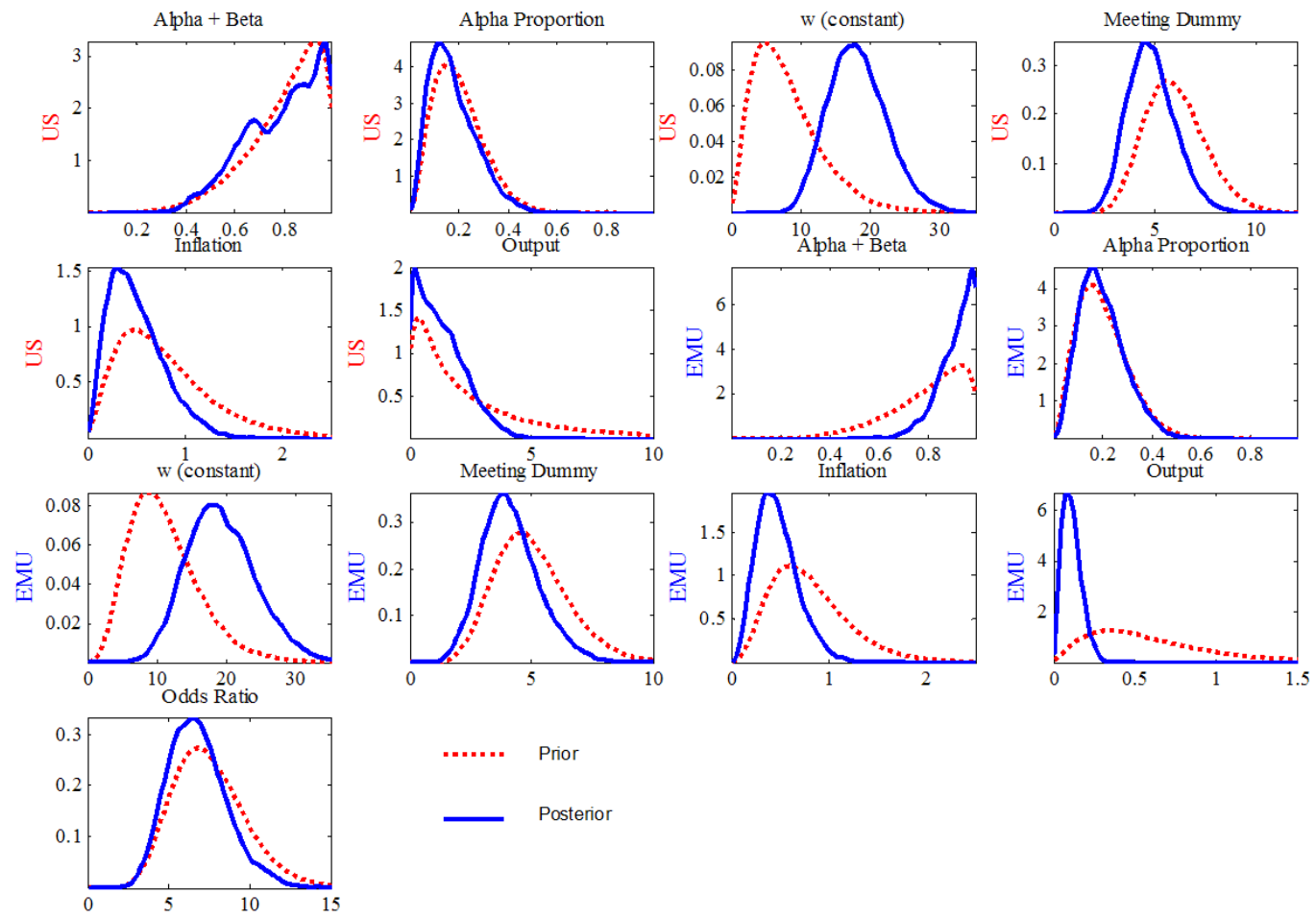

....... Prior

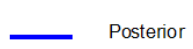

Figure 4: Prior and posterior densities for the basic specification of the BACH model 

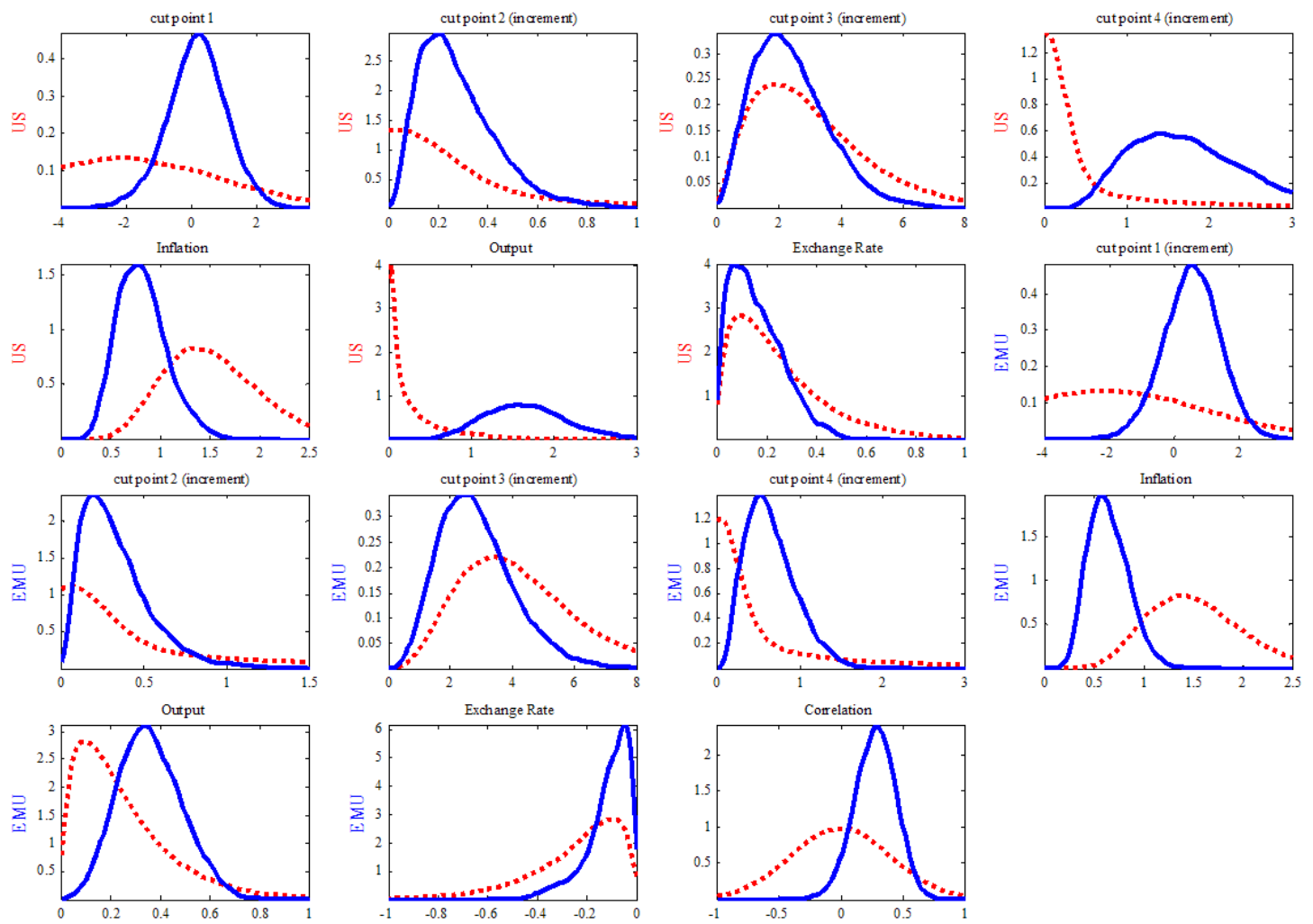

Figure 5: Prior and posterior densities for the basic specification of the CBO Probit model 